\title{
Artigo de revisão: Propriedades biológicas das proteínas e peptídeos do soro do leite
}

\section{caprino}

\author{
Review article: Goat whey biology and bioactive properties of proteins and peptides \\ Artículo de revisión: Propiedades biológicas de las proteínas y péptidos del suero de leche de cabra
}

Recebido: 03/12/2021 | Revisado: 10/12/2021 | Aceito: 17/12/2021 | Publicado: 02/01/2022

Maria Isabel Ferreira Campos

ORCID: https://orcid.org/0000-0002-1274-2146

Universidade Federal da Paraíba, Brasil

E-mail: belcampos.va@gmail.com

Anna Karoline De Sousa Lima

ORCID: https://orcid.org/0000-0001-8008-6745

Universidade Federal da Paraíba, Brasil

E-mail: karol_slima@hotmail.com

José Honório Pereira Lopes Neto

ORCID: https://orcid.org/0000-0002-0002-8324

Universidade Federal da Paraíba, Brasil

E-mail: netoea22@gmail.com

Julia Mariano Caju de Oliveira

ORCID: https://orcid.org/0000-0001-9388-5108

Universidade Federal da Paraíba, Brasil

E-mail: juliacaju0@gmail.com

Tatiane Santi Gadelha

ORCID: https://orcid.org/0000-0001-9451-9820

Universidade Federal da Paraíba, Brasil

E-mail: santi.tatiane@gmail.com

\begin{abstract}
Resumo
O leite caprino é utilizado há décadas em substituição aos demais leites por estar associado a melhor digestibilidade, menor alergenicidade e potenciais benefícios à saúde do consumidor. A indústria láctea ocasionalmente descarta subprodutos como o soro do leite de cabra, um líquido amarelado, que pode ser obtido pela fabricação de queijos ou pela precipitação ácida das caseínas. O soro é a fração solúvel do leite que contém diversos componentes remanescentes notoriamente interessantes, como as proteínas, presentes na forma de um pool proteico, que tem potencial de apresentar diferentes atividades biológicas, bem como, propriedades tecnológicas de grande interesse. A hidrólise das proteínas do soro do leite caprino demonstra ser um processamento eficaz para obtenção de moléculas bioativas que devido a sua funcionalidade tem grande potencial para serem microencapsuladas. Assim essa revisão da literatura de maneira geral compila apenas estudos envolvendo o leite caprino, e faz um apanhado a respeito da composição do leite caprino e o desenvolvimento da caprinocultura leiteira. Bem como busca enfatizar as proteínas e peptídeos do soro do leite caprino e as bioatividades a quais estas são relacionadas, de maneira a gerar um maior entendimento sobre suas características tecnológicas, atividades biológicas e funcionais possibilitando reunir conhecimentos de uma fonte proteica com diversos benefícios a saúde que geralmente é descartada, e pode ser melhor aproveitado pela indústria, proporcionando geração de renda para aqueles que sobrevivem desta atividade agropecuária.
\end{abstract}

Palavras-chave: Proteínas do soro; Componentes funcionais caprinos; Peptídeos bioativos.

\begin{abstract}
Goat milk has been used for decades as a substitute for other milks because it is associated with better digestibility, lower allergenicity and potential health benefits to the consumer. The dairy industry occasionally discards by-products such as goat milk whey, a yellowish liquid that can be obtained by cheesemaking or by acid precipitation of caseins. Whey is the soluble fraction of milk that contains several notoriously interesting remaining components, such as proteins, present in the form of a protein pool, which have the potential to exhibit different biological activities as well as technological properties of great interest. The hydrolysis of goat whey proteins has proven to be an effective process to obtain bioactive molecules that due to their functionality have great potential to be microencapsulated. Thus, this literature review compiles only studies involving goat milk, and summarizes the composition of goat milk and the development of goat dairy farming. As well as seeks to emphasize the proteins and peptides of goat milk whey and the bioactivities to which they are related, in order to generate a greater understanding of their technological characteristics, biological and functional activities enabling gathering knowledge of a protein source with several
\end{abstract}


health benefits that is usually discarded, and can be better used by the industry, providing income generation for those who survive this agricultural activity.

Keywords: Whey proteins; Goat functional compounds; Caprine bioactive peptides.

\section{Resumen}

La leche de cabra se ha utilizado durante décadas como sustituto de otras leches porque se asocia a una mejor digestibilidad, menor alergenicidad y posibles beneficios para la salud del consumidor. La industria láctea desecha ocasionalmente subproductos como el suero de leche de cabra, un líquido amarillento, que puede obtenerse mediante la fabricación de quesos o la precipitación ácida de las caseínas. El suero es la fracción soluble de la leche que contiene varios componentes remanentes notoriamente interesantes, como las proteínas, presentes en forma de pool proteico, que tienen el potencial de presentar diferentes actividades biológicas, así como propiedades tecnológicas de gran interés. La hidrólisis de las proteínas del suero de la leche de cabra demuestra ser un proceso eficiente para obtener moléculas bioactivas que por su funcionalidad tienen un gran potencial para ser microencapsuladas. Así pues, esta revisión bibliográfica recopila únicamente estudios generales sobre la leche de cabra, y hace un repaso de la composición de la leche de cabra y del desarrollo de la ganadería lechera. Además de tratar de destacar las proteínas y péptidos del suero de la leche de cabra y las bioactividades con las que se relacionan, con el fin de generar un mayor conocimiento de sus características tecnológicas, actividades biológicas y funcionales permitiendo reunir el conocimiento de una fuente de proteína con varios beneficios para la salud que normalmente se descarta, y que puede ser mejor aprovechada por la industria, proporcionando la generación de ingresos para los que sobreviven a esta actividad agrícola.

Palabras clave: Proteínas del suero; Componentes funcionales de la cabra; Péptidos bioactivos.

\section{Introdução}

Alimentos funcionais são aqueles que além do seu elevado valor nutricional são capazes de desempenhar funções benéficas na fisiologia do organismo devido à funcionalidade associada a sua composição. Dentre os diversos tipos de alimentos funcionais, as proteínas e os peptídeos derivados de fontes alimentares vêm ganhando destaque nas pesquisas cientificas devido aos diferentes tipos de atividades biológicas ao qual estão relacionados, incluindo atividades antioxidantes, anti-hipertensivas, antitumorais, antibacterianas e imunomodulatórios (Contreras et al., 2011).

Peptídeos bioativos derivados de proteínas do leite tem atraído grande interesse no campo dos alimentos funcionais por serem obtidos através de uma matéria prima de baixo custo e de fácil obtenção, não demonstrando toxicidade e exibirem diferentes atividades biológicas atribuídas a sua potencial habilidade de modulação de rotas metabólicas exercendo um efeito geral benéfico para a fisiologia do indivíduo (Yadav et al., 2015).

A região Nordeste do Brasil possui o maior rebanho caprino por apresentar características propícias para criação destes animais, tais como o clima semiárido e a vegetação caatinga. O leite caprino é responsável por 13,5\% da produção mundial, porém apesar dos benefícios, da relevância e do alto valor nutricional ainda há obstáculos para o aproveitamento e valorização do soro caprino, que muitas vezes é descartado pelas indústrias e cooperativas causando sérios problemas ao meio ambiente e a população. Ademais, as características biológicas e nutricionais do soro do leite caprino, a presença de compostos com propriedades funcionais e a capacidade tecnológica para o desenvolvimento de novos produtos projeta um novo cenário experimental voltado à utilização desta matriz (Lopes et al., 2012; Pulina et al., 2018).

O soro do leite de cabra é um subproduto de fácil obtenção que possui um alto valor nutricional, biológico e uma composição proteica variada e multifuncional com capacidade de ser inserida em contextos biológicos, tecnológicos e nutricionais (Lopes et al., 2012).

A obtenção de peptídeos bioativos (PBA’s) a partir das proteínas do soro do leite por hidrólise a partir de proteases tem se mostrado um processamento eficaz para obtenção de bioativos, contudo estes hidrolisados enfrentam obstáculos para serem comercializados, tais como a alta higroscopicidade, hidrofobicidade, o sabor amargo, a instabilidade, a ocorrência de reações com a matriz alimentar e muitas a digestão completa perdendo assim a sua funcionalidade (Batista et al., 2018). Assim uma das possíveis formas de aumentar a utilização dos hidrolisados é utilizando a tecnologia de encapsulação dos que auxilia no enfrentamento das limitações acima mencionadas, tornando os hidrolisados do soro do leite de cabra um material de alto 
valor biológico para a indústria de alimentos com aplicações na produção de alimentos funcionais (Yadav et al., 2015).

A crescente busca por alimentos que possuem características benéficas à saúde, e contribuam para uma melhor qualidade de vida, prevenindo ou auxiliando no tratamento de doenças, conduz à necessidade de exploração da biofuncionalidade dos alimentos. Esta mudança no perfil de consumo, associada à necessidade de expansão e sustentabilidade da cadeia produtiva do leite caprino, valida os esforços para o estudo aprofundado de características químicas diferenciais naturalmente presentes, assim como para a avaliação de fatores que possam influenciá-las, visando agregar valor ao soro do leite fortalecendo a economia e a competitividade no mercado de laticínios.

Com base nisso, esta revisão de literatura objetiva realizar um apanhado de trabalhos científicos voltados a valorização das proteínas do soro do leite caprino além de delinear aspectos como a composição do leite caprino e o cenário da produção de leite, buscando reunir informações que possam elucidar melhor o entendimento a respeito dos potenciais funcionalidades do soro do leite e assim prospectar o desenvolvimento de novas pesquisas e contribuir para a agregação de valor deste subproduto.

\section{Metodologia}

Neste estudo foi realizada uma revisão da literatura com base em uma extensa pesquisa bibliográfica em confiáveis bases de dados científicos com Science Direct, Scopus, Wiley Online Library e Scientific Electronic Library Online (Scielo). Para a busca dos artigos científicos foram utilizados os seguintes descritores: "whey protein goat milk", "goat milk composition", "caprine milk", "sérum goat", "funcnionality whey protein", "goat milk bioactive”. Assim foram selecionados artigos preferencialmente em língua inglesa e escolhidas as publicações datadas entre os anos de 2011 a 2021 para elaboração de uma revisão focada na composição do leite caprino, nas proteínas do soro do leite caprino e na possível aplicação de seus peptídeos funcionais.

\section{Resultados e Discussão}

\subsection{Resultados e Discussão}

\subsubsection{Caprinocultura Leiteira}

Leites de animais não tradicionais representam cerca de $17 \%$ do total da produção a nível mundial, cerca de 133 milhões de toneladas por ano. Dentre estes animais, as cabras (Capra aegagrus hircus) são responsáveis pela produção de uma quantidade de 12,2 milhões de toneladas métricas de leite sendo produzidas por um rebanho caprino estimado de aproximadamente 780 milhões. Números estes que são uma aproximação do valor real, levando em consideração que a produção de cabras é bastante difundida em países subdesenvolvidos e em desenvolvimento, que não tem informações estatísticas bem registradas para agricultura e pecuária deste setor (Turkmen, 2017; Ranadheera et al., 2019)

A caprinocultura é a atividade agropecuária relacionada à criação de cabras, tanto em ambiente doméstico como por sistemas de produção mais elaborados. As principais raças de cabras criadas para produção do leite são Toggenburg, Saanen, Alpina, sendo a primeira a maior produtora de litros de leite produzidos por dia, aproximadamente 7,5 L/dia (G et al., 2016). No Brasil, em 2020, houve um aumento no rebanho caprino em comparação com 2018 e 2019, batendo a marca de 12 milhões de cabeças de cabra (IBGE, 2020). Sendo na região nordeste o maior contingente de rebanho bem como o maior núcleo produtor de leite, fato esse provavelmente relacionado à capacidade destes ruminantes se adaptarem melhor ao clima semiárido e a vegetação caatinga (Brasil. Ministério da Agricultura, 2000)

A região nordeste é a região que apresenta a maior produção de leite caprino no Brasil, onde os Estados da Paraíba, Ceará e Pernambuco se organizam em uma cadeia produtiva voltada ao desenvolvimento local de cooperativas e associações de pequenos produtores que se inserem no contexto de produção, beneficiamento e comercialização do leite e de produtos a 
partir do leite caprino, como queijos, iogurtes, bebidas lácteas e etc. (Silanikove et al., 2010).

O manejo do rebanho por parte dos criadores se adequa aos sistemas de produção agropecuária destes ruminantes para melhor exploração da atividade leiteira seguindo um fluxo de cadeia produtiva que vai desde o fornecimento de insumos, passando pela cadeia de produtores e criadores que acompanha a dinâmica de unidades de processamento e transformação da matéria prima (carne, leite ou lã) seguindo assim para distribuição desses produtos para um consumidor final (Monteiro et al., 2021). Dadas essas características a cadeia produtiva do leite influencia no beneficiamento de milhares de famílias que, estimuladas pela geração de renda, apoiam-se na criação e fortalecimento de microempresas rurais deste setor do agronegócio (Silanikove et al., 2010; Lopes et al., 2012; Monteiro et al., 2021).

Contudo os produtores enfrentam dificuldades técnicas, econômicas e sociais sofrendo as consequências do desamparo das políticas públicas que possam impulsionar a comercialização, e assim ocasionem o desenvolvimento de uma legislação específica que prospecte a divulgação de produtos caprinos e seus benefícios, passando a tratar esta cadeia produtiva como um negócio em potencial e não apenas como uma atividade de subsistência.

Sendo assim, mais estudos que evidenciem os benefícios do consumo do leite caprino, que proporcionem ideias inovadoras na elaboração de produtos derivados deste leite, agregam valor a essa categoria do agronegócio e voltam à atenção do comércio e da indústria para este setor comercial potencializando sua a inserção no mercado e impulsionando a cadeia produtiva da criação de pequenos ruminantes estimulando assim não só a permanência do homem no campo como possibilitando que esta seja digna e promissora.

\subsubsection{Composição do Leite Caprino}

A composição do leite de cabra é o principal fator que tem levado a maior visibilidade deste tipo de leite, o perfil de ácidos graxos, as proteínas presentes, os menores tamanhos dos glóbulos de gordura, a ausência de aglutinina e a menor quantidade de as1-caseina são propriedades que favorecem a digestibilidade.

O leite caprino apresenta uma coloração branca puro, com odor e sabor diferenciados, devido à presença de ácidos graxos de cadeia curta e média (6-16 carbonos) como os ácidos capróico, caprílico e cáprico onde estes por sua vez são diretamente usados como fonte de energia por serem menores, não se depositando no tecido adiposo e apresentarem potenciais bioatividades como a capacidade de prevenir a resistência à insulina, a esteatose e a inflamação hepática evidenciadas em um modelo animal (Clark \& Mora García, 2017; Delgadillo-Puga et al., 2020).

O perfil de ácidos graxos presentes no leite caprino foi resumido na tabela 1, onde pode ser visualizada a presença do ácido linoleico conjugado (CLA) que se relaciona a diversos efeitos benéficos como a redução do estresse oxidativo, a participação nas reações de inflamação, na síntese de mediadores inflamatórios como os eicosanoides e ácidos araquidônicos, e por desempenhar um importante papel protetivo no sistema nervoso e cardiovascular (Salari et al., 2016; Gumus \& Gharibzahedi, 2021; Mollica et al., 2021). 
Tabela 1. Perfil de ácidos graxos do leite Caprino em g/100g de lipídios.

\begin{tabular}{cc}
\hline Butírico (C4:0) & $\mathbf{2 . 1 8}$ \\
\hline Capróico (C6:0) & 2.39 \\
\hline Caprílico (C8:0) & 2.73 \\
\hline Cáprico (C10:0) & 9.97 \\
\hline Láurico (C12:0) & 4.99 \\
\hline Mirístico (C14:0) & 9.81 \\
\hline Miristoleico (C14:1) & 0.18 \\
\hline Palmítico (C16:0) & 28.00 \\
\hline Palmitoleico (C16:1) & 1.59 \\
\hline Esteárico (C18:0) & 8.88 \\
\hline Oleico $(\mathbf{C 1 8 : 1 )}$ & 19.3 \\
\hline Linoleico $(\mathbf{C 1 8 : 2})$ & 3.19 \\
\hline Linolênico $(\mathbf{C 1 8 : 3 )}$ & 0.42 \\
\hline Linoleico conjugado(C18:2) & 0.70 \\
\hline Pentadecanóico(C15:0) & 0.71 \\
\hline
\end{tabular}

Fonte: Amigo e Fontecha (2011); Watkins et al. (2021).

As proteínas do leite caprino são divididas em dois grandes grupos: as caseínas e as proteínas solúveis ou proteínas do soro do leite. As caseínas são proteínas fosforiladas (nos resíduos seril e, em menor frequência, em resíduos treonil) de estrutura aberta e flexível, e se apresentam na forma de micelas, um agregado supramolecular dinâmico que apresenta partículas porosas, com elevado nível de hidratação que são mantidos juntos pela ação de interações intermoleculares (não covalentes) (Jones et al., 2012; Holt, 2016; Verruck et al., 2019a).

As micelas de caseína são subdivididas em subunidades $\kappa-, \beta-, \alpha$ 1-, $\alpha$ s-, e $\gamma$-caseínas. Para o leite caprino as caseínas representam cerca de 70\% do total proteico, chegando a quantidades em torno de 4g/100 mL (Dalgleish, 2011) A fosforilação presente nas micelas de caseína é responsável pela manutenção da estrutura micelar e pela maior afinidade por cátions bivalentes, como cálcio e magnésio, dessa forma as transformações que venham a ocorrer nessa estrutura por alterações físico-químicas do meio ( $\mathrm{pH}$, temperatura, força iônica, enzimas) é o que pressupõe a aptidão tecnológica do leite para transformação em derivados lácteos ( Dalgleish, 2011; Al-Saadi et al., 2014; N. N. Silva et al., 2019).

Uma das principais características que leva à substituição do leite bovino pelo leite caprino é a menor alergenicidade de suas proteínas devido a polimorfismos genéticos espécie-dependentes. As principais proteínas relacionadas ao desenvolvimento de alergias são a $\alpha$-S1-caseína e a $\beta$-caseína ( Schulmeister et al., 2009; Amalfitano et al., 2020). Para a fração $\alpha$-s1 da caseína, o leite caprino apresenta maior quantidade da fração $\alpha$-S2 do que da $\alpha$-S1 (em comparação ao leite bovino e humano) podendo assim ser uma alternativa para indivíduos que apresentem o desenvolvimento de desordens relacionadas ao consumo do leite bovino (Park et al., 2017)

Outra possível relação é a existência de um genótipo expressado no leite bovino na fração $\beta$-caseína, a qual apresenta duas formas A1 e A2, que diferem entre si devido a substituição na posição 67 do aminoácido histidina (A1) para prolina (A2). A fração A1 da $\beta$-caseína quando passa pela digestão gastrointestinal libera um peptídeo chamado $\beta$-casomorfina-7 (BCM-7) que parece ser o fator primário para o desenvolvimento de problemas digestivos relacionados ao consumo de leite bovino (Park \& Haenlein, 2021).

A lactose é o principal carboidrato presente no leite caprino e está presente em quantidade semelhante as do leite bovino e de camelo, porém em menor concentração do que no leite humano e de ovelha. Ao contrário dos outros macronutrientes é possível perceber que sua quantidade no leite caprino sofre modificações crescentes conforme avança o período de lactação, podendo chegar até cerca de 5\% (Soliman, 2005; Kljajevic et al., 2018). Outros carboidratos presentes no leite caprino são os nucleotídeos, os oligossacarídeos e aqueles conjugados com frações proteicas tais como as glicoproteínas e os glicopeptídeos (Giorgio et al., 2018; Verruck et al., 2019b)

Diversos processos tecnológicos são aplicados baseados em modificações na lactose, Queiroz et al. (2021) realizaram 
a hidrolise enzimática da lactose para obtenção de um leite caprino em pó sem lactose, voltado para consumidores que possuem restrições no consumo deste açúcar. O processo mais comum é à fermentação da lactose para produção de diferentes tipos de produtos, a exemplo da bebida probiótica fermentada com teor reduzido de lactose desenvolvida por Pawlos (2020), do sorvete caprino probiótico formulado por Silva et al., (2015) do kefir e do iogurte probiótico elaborado por Azizkhani et al., (2021).

Com relação aos micronutrientes a tabela 2 resume o quantitativo de minerais e vitaminas presentes no leite caprino, que apresenta uma quantidade mais elevada do que o leite de vaca (chegando a um total de 0,85\%) Conforme descrito na tabela, o ferro e cobre estão presentes em menores quantidades porém, estes possuem melhor bioacessibilidade dos que aqueles provenientes de outros tipos de leite, impactando na maneira com a qual o organismo poderá utiliza-los para os processos digestivos e metabólicos (Ceballos et al., 2009; Amigo \& Fontecha, 2011; Verruck et al., 2019ª; Mehra, et al., 2021) No que diz respeito à composição de vitaminas, a vitamina $\mathrm{A}$ se destaca por apresentar um papel importante nas respostas imunológicas inatas e adaptativas. (Park, 2006; Chauhan et al., 2021).

Tabela 2. Quantitativo de micronutrientes no soro do leite caprino.

\begin{tabular}{l|l}
\hline Vitaminas & Leite Caprino \\
\hline Vit A(UI) & 185 \\
\hline Vit D (UI) & 2.3 \\
\hline Vitamina B1 $(\mathrm{mg})$ & 0.048 \\
\hline Vitamina B2 $(\mathrm{mg})$ & 0.138 \\
\hline Vitamina B3 $(\mathrm{mg})$ & 0.277 \\
\hline Vitamina B5 $(\mathrm{mg})$ & 0.31 \\
\hline Vitamina B6 $(\mathrm{mg})$ & 0.046 \\
\hline Vitamina C(mg) & 1.29 \\
\hline VitaminA B9 $(\mu \mathrm{g})$ & 1.00 \\
\hline VitaminA B7 $(\mu \mathrm{g})$ & 1.5 \\
\hline VitaminA B12 $(\mu \mathrm{g})$ & 0.065 \\
\hline Minerais $(\mathrm{mg})$ & Leite Caprino \\
\hline Cálcio & 134 \\
\hline Fósforos & 121 \\
\hline Magnésio & 16 \\
\hline Potássio & 204 \\
\hline Sódio & 41 \\
\hline Iodo & 0.022 \\
\hline Enxofre & 28 \\
\hline Ferro & 0.05 \\
\hline Cobre & 0.05 \\
\hline Manganês & 0.032 \\
\hline Zinco & 0.30 \\
\hline &
\end{tabular}

Fonte: Park (2012).

A constituição básica do leite caprino pode ser afetada por diversos fatores, em estudo realizado por Bolacali e Küçük, (2012) sobre as características do leite produzido por cabras Saanen, os fatores genéticos: raça e espécie; ambientais: clima e solo; práticas de caprinocultura, sistemas confinado, pasto e misto foram determinantes para alterar a composição. Costa et al., (2021) observaram também a interferência da qualidade do consumo hídrico na qualidade e composição do leite caprino.

Sabendo que a dieta dos animais é um fator que pode alterar a qualidade do leite, diversos estudos reportam as possíveis alterações geradas pela modificação na qualidade da alimentação e observam que mudanças na composição das rações podem ocasionar mudanças no perfil volátil, lipídico, proteico, na estabilidade oxidativa do próprio leite e no desempenho de atividades funcionais como o potencial antioxidante (Razzaghi et al., 2015; Ianni et al., 2021; Mavrommatis \& Tsiplakou, 2020; Mitsiopoulou et al., 2021; Nascimento et al., 2021; Tajaddini et al., 2021). Tais estudos prospectam a otimização da cadeia produtiva do leite, e possibilitam o estudo de modificações que podem melhorar as características da 
economia leiteira aumentando a utilização do leite caprino e difundindo seus benefícios funcionais (Hammam et al., 2021).

As propriedades físicas e químicas do leite caprino estão bem elucidadas por diversos trabalhos (Haenlein \& Wendorff, 2006; Park, 2006), ainda assim estudos recentes buscam observar a consequência de aplicação de diferentes processamentos nas características do leite caprino, como cor, ponto de congelamento, densidade, acidez, pH e na composição centesimal. Razali et al., (2021) observaram o efeito da aplicação da alta pressão em substituição a pasteurização do leite caprino e concluíram que a aplicação de uma pressão menor que $400 \mathrm{MPa} / 5 \mathrm{~min}$, reduz a contagem de placas a valores indetectáveis e possibilita menores alterações de viscosidade, sólidos solúveis totais, $\mathrm{pH}$ e cor total prolongando a estabilidade durante a vida de prateleira.

Dessa forma, a aplicação de processamentos no leite embora desejável do ponto de vista industrial, comercial e econômico, devem ser bem estudadas para otimizar as condições e características de modo a atender a demanda comercial/industrial bem como a manutenção das características nutricionais e sensoriais.

Em um estudo recente vários tipos de processamentos foram avaliados no leite de cabra: a aplicação de calor, o desnate, a concentração a vácuo e a microfiltração e como estes alteram as propriedades físico-químicas como estabilidade ao calor, cor, atributos reológicos e alterações nos componentes bioativos. Diante disso, os autores verificaram que todas as intervenções tiveram efeito significativo sobre o teor de gordura, proteína e cinzas, o aquecimento e concentração levaram a diminuição do $\mathrm{pH}$ enquanto que o desnate foi o que menos afetou os componentes bioativos. $\mathrm{O}$ tratamento térmico causou adiamento da gelificação do coalho e formou um coágulo menos resistente. Do ponto de vista microbiológico, o leite de cabra microfiltrado reduziu as contagens de bactérias e coliformes totais (Saipriya et al., 2021).

\subsubsection{Soro do leite, caracterização e aplicações tecnológicas de suas proteínas}

Apesar da produção do soro do leite pela produção de queijos ser o processo mais popular, existem outros tipos de obtenção, dentre elas: a coagulação enzimática, processo empregado na produção de queijos, que consiste na adição de uma enzima, que ocasiona a precipitação das caseínas e separação do soro; a precipitação ácida quando o pH baixa até atingir o ponto isoelétrico da caseína, ocasionando a insolubilidade e coagulação, se separando da fração solúvel o soro; e a separação física das micelas de caseína por microfiltração, baseado na diferença de tamanho das caseínas em comparação com as proteínas do soro (Smithers, 2008; Yadav et al., 2015).

Independentemente do processo, irá ocorrer à formação de um concentrado de micelas caseínicas (precipitado) e do soro do leite (sobrenadante), um liquido amarelado devido a presença de riboflavina. A produção enzimática do soro resulta em um subproduto conhecido como "soro doce", devido a coagulação ocorrer em torno de $\mathrm{pH}$ 6,5 próximos a neutralidade. A obtenção por abaixamento do $\mathrm{pH}$ produz o "soro ácido", pois é obtida em pH em torno de 4.6-5.0, após a precipitação o volume de soro obtido representa cerca de $80 \%$ do volume inicial do leite e esse volume muitas vezes é descartado pelas indústrias ocasionando a poluição de solos e águas (Sgarbieri, 2004; Kosseva et al., 2009).

Dessa forma, fatores como o elevado valor nutricional do soro do leite, a capacidade funcional, tecnológica que possibilita aplicações industriais juntamente com as prospecções científicas indicam que este subproduto pode contribuir de forma benéfica para a fisiologia do corpo e manutenção da saúde, despertando um caminho conjunto entre o interesse científico e o envolvimento comercial das indústrias de laticínios no soro do leite (J et al., 2015).

A composição do soro do leite de cabra pode ser afetada de acordo com o tipo de processamento do leite, da raça dos animais e de fatores genéticos, mas de um modo geral apresenta 93-94\% de água e nutrientes remanescentes do leite como a lactose, proteínas solúveis, minerais, ácidos orgânicos, baixo teor de gordura e proteínas de membrana do glóbulo de gordura e alguns componentes nitrogenados não proteicos tais como ureia e ácido úrico, além de vitaminas solúveis, em especial as do complexo B (Panesar et al., 2013; Saipriya et al., 2021). 
Blanca Hernández-Ledesma et al., 2011 relata que a composição do soro do leite, proveniente de ovinos e caprinos, apresenta particularidades no que diz respeito à capacidade do soro destas espécies em modular a atividade de funções fisiológicas, e ainda ser potencialmente capaz de reduzir o risco de doenças crônicas, atribuindo-se ao soro do leite destes animais, o título de "alimentos funcionais". Além disso, as proteínas do soro do leite vêm sendo descritas como melhores fontes proteicas que outros tipos de proteínas como caseína, proteínas do ovo, da soja, de carnes reforçando assim a qualidade nutricional dessas na dieta da população (Mangano et al., 2019).

Dentre os constituintes do soro do leite, as proteínas vêm ganhando cada vez mais notoriedade devido às atividades biológicas as quais são capazes de desempenhar e com isso podem ser utilizadas para formulação de diversos produtos com propriedades benéficas à saúde. Além disso, as proteínas do soro também apresentam potencial tecnológico para a indústria de alimentos (capacidade emulsificante, espumante, geleificante) devido as suas excelentes propriedades funcionais correlacionadas às suas características físicas, químicas e estruturais (Pescuma et al., 2010).

As proteínas do soro do leite caprino em sua maioria são sintetizadas na glândula mamária do animal e sua composição proteica quantitativa indica ser uma mistura heterogênea de diferentes proteínas individuais, onde cada uma apresenta diferenciação nas propriedades funcional, fisiológica e nutracêuticas (Yadav et al., 2015). Estas são divididas em dois diferentes grupos: as proteínas majoritárias, que inclui a $\beta$-lactoglobulina $(\beta-\mathrm{Lg})$, a proteína de maior concentração no soro, seguida pela lactoalbumina $(\alpha-\mathrm{La})$; e as proteínas minoritárias que incluem as Imunoglobulinas, sérum albuminas, o sistema lactoperoxidase, proteases e peptonas, lisozima, lactoferrina e eventualmente, macro peptídeos de caseína (HernándezLedesma, 2011). A tabela 3 resume as características químicas e físicas de cada proteína anteriormente mencionada.

Além do perfil proteico, o soro do leite possui todos os aminoácidos essenciais (na quantidade recomendada ou acima), tais como fenilalanina e tirosina e elevadas concentrações de triptofano, cisteína, leucina, isoleucina e lisina (Sgarbieri, 2004).

Tabela 3. Características químicas e físicas das proteínas do soro do leite.

\begin{tabular}{l|c|c|c|c}
\hline \multicolumn{1}{c|}{ Proteína } & $\begin{array}{c}\text { Ponto } \\
\text { Isoelétrico }\end{array}$ & $\begin{array}{c}\text { Peso } \\
\text { Molecular } \\
(\mathrm{kDa})\end{array}$ & $\begin{array}{c}\text { Quantidade de } \\
\text { aminoácidos }\end{array}$ & $\begin{array}{c}\text { Quantidade } \\
(\%)\end{array}$ \\
\hline$\beta$-lactoglobulina & $5,3-5,5$ & $18,3 \mathrm{Da}$ & 162 & $40-50$ \\
\hline$\alpha$-lactoalbumina & 4,8 & 14 & 123 & $10-20$ \\
\hline Imunoglobulinas & $5,5-8,3$ & $150-900$ & - & 8 \\
\hline Albumina sérica & $4,7-4,8$ & 66 & 580 & $10-15$ \\
\hline Lactoperoxidase & 9,5 & 78 & 610 & 1 \\
\hline Proteoses/ peptonas & - & 20 & - & 0,2 \\
\hline Lactoferrina & 8 & $76^{\mathrm{b}}$ & 691 & 1 \\
\hline $\begin{array}{l}\text { Macropeptídeos } \\
\text { de caseína }\end{array}$ & $4,3-4,6$ & 6,8 & 64 & 10 \\
\hline
\end{tabular}

Fonte: Autores (2012).

Apesar dos benefícios, da relevância tecnológica e do alto valor nutricional há limitações na utilização in natura do soro do leite devido a sua alta atividade de água acarretando em significativa perecibilidade, elevada diluição dos seus componentes e seu elevado teor de lactose ocasiona uma demanda biológica e química de oxigênio bastante acentuada (Kareb \& Aïder, 2019). Contudo para evitar à perda do produto e da qualidade nutricional, a indústria de alimentos utiliza técnicas de processamento como a evaporação, spray-drying, liofilização, separação por membranas (ultrafiltração, microfiltração e diafiltração) que geram produtos como o concentrado do soro do leite (ainda há a presença de outros componentes do soro 
como lactose e gordura, contudo a maior parte da água foi retirada), a proteína isolada de soro do leite (proteína na sua forma mais pura), a lactose isolada e outras frações (Brans et al., 2004; Mollea et al., 2013; Batista et al., 2018).

Processos biotecnológicos são frequentemente empregados no soro, onde este é utilizado como substrato de microorganismos e enzimas para obtenção de produtos finais com elevado valor biológico, nutricional e tecnológico (Kosseva et al., 2009; Sousa et al., 2012; Panesar et al., 2013). Um exemplo é a proteína hidrolisada do soro do leite que é comercializada visando uma rápida digestão e absorção das proteínas e aminoácidos. (Sousa et al., 2012; Kanda et al., 2013).

Correlações entre o desempenho funcional das proteínas em suas estruturas nativas são pontuais na literatura uma vez que a bioatividade tem sido frequentemente relacionada a obtenção de peptídeos bioativos (PBA's) a partir das proteínas do soro do leite. Peptídeos bioativos podem ser definidos como fragmentos proteicos específicos, que contém cerca de 2 a 20 resíduos de aminoácidos, e proporcionam desejáveis efeitos positivos no funcionamento corporal influenciando na promoção da saúde (Minj \& Anand, 2020). Outra definição traz que os peptídeos apresentam atividade similar a uma droga ou hormônio, que eventualmente modulam uma função fisiológica ao se ligarem a receptores específicos da célula alvo, levando a indução de respostas fisiológicas (Haque \& Chand, 2008).

Estas pequenas sequências de aminoácidos quando presentes na proteína nativa não são capazes de desempenhar funcionalidade necessitando assim serem liberados na forma de peptídeos por reações de quebra das ligações peptídicas da proteína original. Estas reações podem ser desencadeadas por diversos mecanismos, tais como: enzimas digestivas, ou pela atividade proteolítica de micro-organismos, síntese química e/ou através da ação de proteases vegetais ou microbianas (Korhonen \& Pihlanto, 2006)

Diversos efeitos funcionais dos PBA's de hidrolisados da proteína do soro têm sido descritos na literatura tais como efeitos antioxidantes, antiproliferativos e antibacterianos, imunomoduladores, antidiabéticos, anticolesterolêmicos, efeitos benéficos na microbiota intestinal, efeitos no sistema nervoso como inibidores e estimulantes opióides (Mann et al., 2019; Mehra et al., 2020; Kumar, et al., 2021)

\subsection{Atividades funcionais do soro do leite}

A seguir serão discutidas as atividades funcionais mais relevantes das proteínas do soro do leite caprino e seus peptídeos.

\subsubsection{Atividade de inibição da ECA}

A enzima conversora de angiotensina (ECA) atua no sistema renina-angiotensina-aldosterona (RAAS) e no sistema de óxido nítrico quinina (KNOS), agindo como um potente vasoconstrictor e consequentemente aumentando a pressão arterial. Dessa forma, moléculas capazes de inativar esta enzima podem regularizar a pressão arterial e ajudar a manter o funcionamento do sistema cardiovascular (Ibrahim et al., 2017; Xia et al., 2020).

Proteínas e peptídeos naturalmente presentes, ou obtidos pela hidrólise do leite caprino vem sendo reportados por desempenharem até 67\% de inibição da ECA (Koirala et al., 2021). Quando submetidas a hidrólise com pepsina, as proteínas do soro do leite demonstraram maiores teores de inibição da ECA do que quando comparadas as proteínas nativas, sendo possível identificar um peptídeo do soro proveniente de $\beta$-lactoglobulina (no fragmento PEQSLACQCL, resíduo 113-122) com potente inibição da ECA (Ibrahim et al., 2017). O tamanho dos peptídeos e sua carga residual demonstra ser um fator interferente na inibição da ECA, como observado por Moreno-Montoro et al., (2017) peptídeos menores e com cargas não básicas demonstraram melhores valores de inibição e também melhores resultados de atividade antioxidante.

A fermentação por bactérias ácido láticas (BAL) também ocasiona a produção de peptídeos bioativos, podendo ser empregadas na produção de derivados do leite caprino com propriedades funcionais, como queijos, iogurtes dentre outros 
(Rubak et al., 2021; Y. Xia et al., 2020)

\subsubsection{Atividade antibacteriana}

O pool proteico do soro do leite vem sendo relacionado a inibição do crescimento de micro-organismos oferecendo assim um sistema protetivo naturalmente presente que age contra bactérias patogênicas. As proteínas lactoferrina, lisozima, lactoperoxidase e as imunoglobulinas, bem como de peptídeos obtidos a partir das proteínas do soro do leite caprino vem sendo relatados serem potencialmente antimicrobianos (Mann et al., 2019; Soloshenko et al., 2020).

Sabendo que o soro do leite caprino apresenta uma composição variada de proteínas Medeiros et al., (2018) testaram o potencial bacteriostático frente a bactérias Gram-positivas (Staphylococcus aureus) e Gram-negativas (Pseudomonas aeruginosa e Escherichia coli) das proteínas intactas e de suas frações, observando assim uma sinergia entre proteínas e peptídeos na obtenção melhores resultados quando comparados as suas formas isoladas.

Peptídeos antibacterianos possuem algumas características especiais: são geralmente menores que $10 \mathrm{kDa}$, o que possibilita sua entrada na célula bacteriana; possuem aminoácidos de caráter hidrofóbico; apresentam carga residual catiônica que favorece seletivamente interações eletrostáticas das estruturas $\alpha$-hélice e folhas- $\beta$ com as membranas aniônicas das bactérias. Todos estes aspectos favorecem a permeabilidade dos peptídeos para o interior das bactérias ocasionando a lise e morte celular (Almaas et al., 2011; Esmaeilpour et al., 2017).

Dessa forma a obtenção de peptídeos pela hidrolise do soro do leite caprino demonstra ser uma importante ferramenta para obtenção de peptídeos com potencial antibacteriano, uma vez que para diferentes cepas microbianas foi observada melhor inibição do crescimento quando o soro do leite hidrolisado foi testado em comparação ao não hidrolisado, exibindo melhores potenciais de inibição para as bactérias Salmonella typhimurium, Staphylococcus aureus, Escherichia coli e Bacillus cereus (Lestari \& Suyata, 2019). As proteínas majoritárias $\beta$-lactoglobulina e $\alpha$-lactoalbumina possuem a sequência de aminoácidos Val-Ala-Gly-Thr-Trp-Tyr que tem sido caracterizada por possuir atividade antimicrobiana, logo a hidrólise destas proteínas pela Alcalase ${ }^{\circledR}$ possibilitou a liberação de dois peptídeos antimicrobianos (Osman et al., 2016).

\subsubsection{Atividade Antifúngica}

Os fungos toxigênicos são contaminantes bastante presentes nos alimentos que prejudicam o armazenamento e a vida de prateleira de vários tipos de gêneros alimentícios trazendo problemas à segurança alimentar, causando perdas econômicas e sendo um risco em potencial a saúde pública. Estes tipos de fungos possuem a capacidade de produzir toxinas potencialmente cancerígenas que vão se acumulando no organismo e podem levar a consequências agudas e crônicas perigosas. A Ochratoxina A, por exemplo, é um metabólito secundário produzido pelos gêneros Penicillium e Aspergillus que apresentam danos aos rins, toxicidade ao sistema imune, inibição da síntese macromolecular, aumenta a peroxidação lipídica e inibe a respiração mitocondrial (Adeyeye, 2016; Bui-Klimke \& Wu, 2015; Luz et al., 2020).

Sabendo da capacidade do leite caprino em demonstrar um efeito antimicrobiano, estudos envolvendo atividades antibacterianas e antivirais são bem descritos na literatura, contudo, propriedades antifúngicas destas proteínas vêm sendo recentemente avaliadas. Luz et al., (2020) obteve hidrolisados proteicos do soro do leite e avaliou atividade antifúngica (contra Penicillium spp.), caracterizou os peptídeos obtidos e os incorporou na formulação de pão pita como um bioconservante. Este estudo observou que houve inibição por parte das proteínas do soro do leite caprino não só dos fungos como na produção de micotoxinas, onde 27 peptídeos antibacterianos puderam ser caracterizados e influenciaram positivamente na vida e prateleira dos pães.

Propriedades antifúngicas das proteínas do soro do leite caprino também foram observadas quando o soro foi fermentado por diferentes cepas de Lactobacillus plantarum, os autores testaram 28 cepas dos fungos Aspergillus, Penicillium 
e Fusarium por 72 horas de incubação, onde observaram que a escolha da cepa foi crucial para o desenvolvimento da inibição e os gêneros com melhores valores de concentração inibitória mínima (CIM) foram Fusarium genus e Aspergillus steynii, chegando a $1.95 \mathrm{~g} / \mathrm{L}$, ressaltando assim o uso de bactérias ácido láticas em proteínas pra promover a capacidade antifúngica do soro do leite de cabra (Izzo et al., 2020).

\subsubsection{Atividade Antiviral}

Dentre as doenças virais a Covid-19 trouxe consequências em várias esferas do cotidiano tendo implicações médicas, científicas, biológicas, sociais, econômicas, políticas, culturais e históricas. Assim, surgiu uma necessidade de realizar aprofundamento, de forma rápida, nos conhecimentos relacionados à prevenção, obtenção de vacinas e no tratamento, que pudessem frear o avanço da doença e as mortes ao redor do mundo.

A potencialização da doença Covid-19 está relacionada a alguns fatores como a furina (uma serina endopeptidase) que facilita a transmissão do vírus ao clivar os sítios de ligação $\mathrm{S} 1$ deixando o sítio $\mathrm{S} 2$ expostos, e duas proteínas que funcionam como receptores do vírus na célula hospedeira a DPP-4/CD26 (uma proteina transmembrana do tipo II) e a enzima conversora de angiotensina-ECA (Coutard et al., 2020; Hoffmann et al., 2020; Vankadari \& Wilce, 2020).

A estrutura do SARS-CoV-2 inclui as proteínas Spikes, associadas à capacidade de entrada do patógeno nas células humanas, o domínio de ligação ao receptor S1 e o domínio S2, que medeia a integração do vírus na célula hospedeira parecem ser as 3 principais formas de propagação da replicação do vírus (Coutard et al., 2020; Kong et al., 2020; S. Xia et al., 2020).

Dessa forma moléculas que possam impedir a ligação do sitio ativo do vírus e inibir a replicação tem ganhado notoriedade, onde estudos in sílico vem sendo desenvolvidos baseados na inibição das proteínas furina, DPP-4 e ECA. Sabendo que os peptídeos derivados do soro do leite podem inibir a ECA, Çakır et al., (2021) hidrolisou o soro do leite caprino com tripsina e sequenciou os peptídeos obtidos, observando assim a partir de técnicas de bioinformática e docking molecular que seis peptídeos derivados da beta-lactoglobulina podem inibir a ECA, a DPP-4 e a enzima sérica furina, onde dois potenciais peptídeos (ALMPHIR e IPAVFK) podem ser candidatos promissores em estudos in vitro e in vivo no tratamento da síndrome respiratória causada pelo SARS-CoV-2.

\subsubsection{Atividade antioxidante e imunomodulatória}

No que diz respeito a capacidade antioxidante dos peptídeos do soro de leite e o mecanismo de ação destes fragmentos proteicos tem sido relatado estar relacionado a mecanismos de "radical scavenger" ou seja, inativação das espécies reativas do oxigênio, bloqueio dos radicais livres, agindo assim na inibição da cadeia reacionária da oxidação. Outro mecanismo de ação diz respeito à quelação dos peptídeos com íons metálicos, é ainda relatado a possibilidade de ocorrer à combinação dos dois mecanismos de ação a depender do peptídeo (Zhou et al., 2012).

Os peptídeos antioxidantes geralmente têm maior número de grupos ionizáveis, para que possam desencadear as reações de oxirredução, com maior exposição de grupos hidrofóbicos em sua molécula, apresentando frequentemente cadeias com resíduos de 5-11 aminoácidos. A forma como esses peptídeos realizam a inibição da oxidação vai depender da sequência dos aminoácidos destas moléculas (Sarmadi \& Ismail, 2010; Zhou et al., 2012).

Entre as metodologias mais utilizadas, estão àquelas baseadas na capacidade antioxidante equivalente de Trolox (TEAC) utilizando o radical ABTS e DPPH, e para avaliar a quelação com íons metálicos é comum a utilização do teste de poder antioxidante de redução de íons férricos (FRAP) e o método ORAC que mede a inibição baseado no radical peroxil e na transferência de átomos de hidrogênio (Alves et al., 2010). Koirala et al., (2021) observou que os hidrolisados da proteína do soro do leite caprino têm a capacidade antioxidante aumentada quando tratados por ultrassonicação. Provavelmente o potencial antioxidante destas proteínas está relacionado aos aminoácidos metionina e cisteína, presentes nas proteínas $\beta$-Lactoglobulina, 
$\alpha$-Lactoalbumina, BSA e a lactoferrina (Meng et al., 2021).

A capacidade antioxidante frequentemente está relacionada com efeitos imunomodulatórios, onde foi observado que a administração da proteína do soro do leite de cabra em ratos idosos influenciou em menores concentrações de malonaldeído (MDA), e maiores concentrações da enzima superóxido dismutase (SOD). Além disso, efeitos a nível imunológico foram observados, tais como a estimulação de imunoglobulina $\mathrm{G}(\mathrm{IgG})$, menores concentrações de citocinas inflamatórias como as interleucinas -2 e 6 (IL-2 e IL 6) e o aumento do peso do timo (órgão relacionado a função imunológica) (Z. Ma et al., 2021).

Peptídeos bioativos habitualmente podem apresentar propriedades multifuncionais, por exemplo, a maioria dos peptídeos que são capazes de desempenhar atividade antioxidante também pode inibir a enzima conversora de angiotensina (ECA), modular respostas imunológicas (B. Hernández-Ledesma et al., 2008).

\subsubsection{Atividade antiproliferativa e antitumoral}

Devido ao aumento expressivo na incidência de casos de câncer no mundo, as pesquisas têm buscado encontrar moléculas que sejam capazes de agir de modo a diminuir a proliferação de células cancerígenas. Há um crescente interesse em investigar metabólitos naturais que modulem biomarcadores de células cancerígenas, onde as proteínas e peptídeos vêm demonstrando o seu potencial nutracêutico em atuar nos diferentes estágios do câncer, incluindo iniciação, promoção e progressão (De Mejia \& Dia, 2010; Sung et al., 2021).

Dessa forma a proteína do soro de leite tem sido estudada por apresentar uma potencial atividade antitumoral/antiproliferativa que tem sido respaldada com evidências científicas como a quantidade significativamente alta dos aminoácidos cistina e cisteína e de dipeptídeos $\gamma$-glutamilcisteína, que são substratos eficientes para a síntese de glutationa. (Brandelli et al., 2015).

Em outro estudo Attaallah et al., (2012) evidenciou a ocorrência de um menor número de focos tumorais quando ratos portadores de câncer de cólon foram alimentados com o hidrolisado de proteína de soro do leite indicando que a proteína do soro é superior a outras proteínas dietéticas para supressão do desenvolvimento do tumor.

Medeiros et al., (2018) verificou a capacidade do soro do leite caprino em exercer efeitos citotóxicos frente a células de glioma de rato $\mathrm{C} 6$. Estes autores observaram taxa de autólise celular superior a $70 \%$ para células cancerígenas a concentrações de 0,05 e $0,1 \mu \mathrm{g} / \mathrm{mL}$ do soro caprino.

Dentre as proteínas do soro do leite, a lactoferrina tem sido o enfoque das pesquisas pois resultados promissores atrelados a funcionalidade desta proteína mostram a sua capacidade de inibir tumores intestinais e possivelmente outros tumores (De Mejia \& Dia, 2010). Acredita-se que o potencial de ação se dê pela atividade do peptídeo lactoferricina (LFcin), derivado da lactoferrina, que atua de diversas maneiras: por indução de apoptose, modulação de enzimas metabolizadoras de carcinogênicos, bloqueando o ciclo celular, modificando a expressão gênica e prevenindo a angiogênese (Gifford et al., 2005)

Estudos in vitro apontam que a LFcin tem potente atividade sobre linhagens celulares de diversos tipos de câncer, dentre estes de mama, de cólon, fibrossarcoma, leucemia, câncer de boca e células de câncer de ovário. Um resultado importante é que a ação se limita as células cancerígenas e não prejudica linfócitos normais, fibroblastos, células endoteliais ou epiteliais (Furlong et al., 2010).

A propriedade seletiva na ação da LFcin parece ser devido ao seu caráter fortemente catiônico, possibilitando assim a interação com em células cancerígenas carregadas negativamente, resultando na desestabilização das membranas celulares. O não prejuízo à membrana celular de células saudáveis se dá devido a carga liquida neutra destas, mantendo-as poupadas (De Mejia \& Dia, 2010). 


\subsubsection{Influência no microbioma intestinal}

A microbiota intestinal é dita como um "órgão" dinâmico e metabólico que exerce diversas funções a nível local e influencia na resposta nutricional, no ciclo circadiano, no metabolismo e na imunidade (Tilg et al., 2020). Logo, a dieta em conjunto com outros fatores pode interferir na composição do microbioma, portanto as proteínas do soro caprino podem ser uma opção eficaz para ocasionar benefícios na microbiota do intestino, onde peptídeos probióticos podem promover o bemestar ao influenciar no potencial de redução-oxidação e equilíbrio entre as bactérias intestinais (Lynch \& Pedersen, 2016; Araújo et al., 2017).

Proteínas do soro do leite caprino quando usadas como suplementos para ratas e filhotes desempenharam um efeito positivo na composição da microbiota fecal, na morfologia intestinal, na redução induzida no ganho de peso e gordura visceral demonstrando assim aptidão destas proteínas em desempenhar efeitos no microbioma (Costa Paulino et al., 2019). Outro estudo evidencia a modulação intestinal do leite caprino em diferentes fases de maturação, onde foi observado o aumento da quantidade de bactérias presentes no intestino, tais como Lactobacillus, Muribaculum e Alistipes, podendo este ser uma importante fonte de probióticos (Liu et al., 2021).

A modulação intestinal está intrinsicamente relacionada com alterações em marcadores imunomodulatórios e de inflamação, podendo ser evidenciado pela ação do leite caprino e das proteínas em estudos que envolvem modelos animais com colite, onde observaram uma melhora significativa de diversos parâmetros inflamatórios como a atividade da mieloperoxidase, regulação negativa da expressão gênica de vários marcadores pró-inflamatórios, como IL-1ß, IL-6, IL-17, TNF- $\alpha$, iNOS, MMP-9, ICAM-1, inibição das vias de sinalização de NF-אB p65 e p38 MAPK, redução do malonaldeído e aumento da glutationa, assim como na manutenção da citoarquitetura colônica e na diminuição da expressão da ciclooxigenase-2 e da óxido nítrico sintase induzível além de aumentar a expressão de proteínas como mucinas, proteínas de ocludina (Assis et al., 2016; Araújo et al., 2017).

\subsubsection{Hidrolisados da proteína do soro do leite}

Embora as proteínas do soro do leite sofram ataque por enzimas durante a digestão no trato gastrointestinal, esta não é suficiente para garantir um possível efeito fisiológico decorrentes da sua catálise, uma vez que as proteínas podem ser totalmente digeridas liberando os aminoácidos livres para absorção no intestino, dessa forma realizar a hidrolise destas proteínas em escala laboral se tornou um trabalho proveitoso e útil para a produção de peptídeos bioativos.

Assim, em uma escala industrial ou laboratorial, podem ser utilizadas uma enzima ou combinações entre duas ou mais enzimas para a reação, a depender da necessidade do processamento. Outra característica favorável da aplicação da hidrólise nas proteínas do soro do leite é a possibilidade de aperfeiçoar algumas características que podem vir a interferir na velocidade e na efetividade da reação, tais com: a adequação do $\mathrm{pH}$ da solução contendo o substrato, o tempo de reação, a temperatura aplicada e a relação entre a concentração de enzima e substrato. Naik et al., (2013) observaram que a razão enzima/substrato e o pH foram os fatores de maior influência no grau de hidrólise de proteínas do soro hidrolisadas por tripsina.

Diferentes tipos de enzimas proteolíticas podem ser empregadas, tais como as proteases de origem microbiana como a subtilisina (conhecida comercialmente como Alcalase ${ }^{\circledR}$, produzida pela bactéria Bacillus licheniformis), de origem vegetal, como a bromelina e a papaína, ou enzimas de origem animal, por exemplo, as que participam da digestão no trato gastrointestinal: tripsina, pepsina (Zhang et al., 2013).

Silvestre et al., (2012) investigaram os melhores parâmetros de obtenção do perfil peptídico e da atividade de inibição da ECA de proteínas hidrolisadas do soro do leite concentrado utilizando papaína e pancreatina. Os resultados deste trabalho mostram que as condições de hidrolise são parâmetros fundamentais na obtenção de um perfil peptídico adequado, e que a hidrolise utilizando papaína gerou o melhor perfil de peptídeos, mas ambas as enzimas demonstraram serem capazes de gerar 
peptídeos com atividade inibidora da ECA.

Em outro estudo Demers-Mathieu et al., (2013) avaliaram a atividade antibacteriana de peptídeos obtidos quando o soro do leite isolado foi hidrolisado por tripsina e quimiotripsina. Os resultados mostram que os peptídeos derivados de $\beta$ Lactoglobulina foram capazes de inibir o crescimento de Listeria monocytogenes e Staphylococcus aureus mas não demonstraram atividades frente a diferentes cepas de Escherichia coli.

Lacroix e Li-Chan, (2013) hidrolisaram as proteínas isoladas do soro do leite utilizando pepsina para verificar se os peptídeos inibiam a ação da enzima dipeptidil peptidase (DPP-IV) e $\alpha$-glicosidase. Todos os hidrolisados demonstraram serem capazes de inibir a DPP-IV, sendo o hidrolisado de alfa-Lactoalbumina o que demonstrou melhor potencial. Com relação à inibição da $\alpha$-glicosidase os hidrolisados das proteínas majoritárias demonstraram atividade, sugerindo assim que os peptídeos gerados podem regular a glicemia.

A utilização comercial dos hidrolisados da proteína do soro é ainda emergente, mas já tem sido empregada para formulação de produtos funcionais, utilizando estes como enriquecimento de produtos ou de forma individual, como pode ser observado na Tabela 4. Embora haja potencial para utilização dos peptídeos bioativos como ingrediente alimentar muito ainda falta ser pesquisado de modo a obter processos de produção economicamente rentáveis, e assim acelerar o desenvolvimento de produtos funcionais a partir destes hidrolisados.

Tabela 4. Produtos comerciais com hidrolisados de proteína do soro do leite ou peptídeos isolados.

\begin{tabular}{|c|c|c|c|c|}
\hline Produto & Fabricante & Tipo de produto & Proteína/Peptídeo & Alegação de saúde \\
\hline $\begin{array}{l}\text { BioZate }{ }^{\circledR} \text { product } \\
\text { line }\end{array}$ & \multirow[b]{2}{*}{ Davisco, USA } & \multirow[b]{2}{*}{$\begin{array}{l}\text { Isolado da proteína do soro do } \\
\text { leite hidrolisada }\end{array}$} & Fragmentos de $\beta$-lactoglobulina & Redução da pressão arterial \\
\hline BioPureGMPтм & & & GMP f (106-169) & $\begin{array}{c}\text { Prevenção de cáries, } \\
\text { modulação da coagulação } \\
\text { sanguínea, antibacteriano, } \\
\text { antiviral. }\end{array}$ \\
\hline Vivinal ${ }^{\circledR}$ ALPHA & $\begin{array}{c}\text { Borculo Domo } \\
\text { Ingredients (BDI), the } \\
\text { Netherlands } \\
\end{array}$ & $\begin{array}{l}\text { Hidrolisado da proteína do soro } \\
\text { do leite como ingrediente }\end{array}$ & $\begin{array}{l}\text { Peptídeo derivado do soro do } \\
\text { leite }\end{array}$ & Relaxamento e sonolência \\
\hline Praventin $^{\mathrm{TM}}$ & $\begin{array}{l}\text { DMV International, the } \\
\text { Netherlands }\end{array}$ & Cápsula de suplemento alimentar & Lactoferrina & Redução da acne \\
\hline Dermylex ${ }^{\mathrm{TM}}$ & Advitec, Inc., Canada & Tablete de suplemento alimentar & $\begin{array}{c}\text { Extrato do soro do leite XP- } \\
828 \mathrm{~L}\end{array}$ & $\begin{array}{c}\text { Redução dos sintomas de } \\
\text { Psoríase }\end{array}$ \\
\hline HilmarTM8390 & Hilmar Ingredients, USA & Suplemento alimentar & $\begin{array}{c}\text { Proteína do soro do leite } \\
\text { hidrolisada }\end{array}$ & $\begin{array}{l}\text { Inibição das enzimas ACE e } \\
\text { DPP-IV }\end{array}$ \\
\hline NOP-47"M & $\begin{array}{c}\text { Glanbia Nutritionals, } \\
\text { USA }\end{array}$ & $\begin{array}{l}\text { Suplemento alimentar e } \\
\text { farmacêutico }\end{array}$ & $\begin{array}{l}\text { Peptídeo derivado do soro do } \\
\text { leite }\end{array}$ & $\begin{array}{l}\text { Propriedades anti- } \\
\text { inflamatórias }\end{array}$ \\
\hline
\end{tabular}

Fonte: Ballard et al., (2009); Korhonen, (2009); Lacroix et al., (20160.

Após a obtenção dos hidrolisados, diversas técnicas de proteômicas, metabolômica e possível interatoma podem ser empregadas de modo a identificar os peptídeos, e a partir de sua sequência correlaciona-los com sua possível funcionalidade. Assim métodos in silico utilizando ferramentas de bioinformática e aliados aos testes in vivo podem ser aplicados para possibilitar a confirmação da alegação de saúde destas moléculas, para tanto são utilizadas técnicas cromatográficas, métodos de separação por membranas, sequenciamento para identificação dos peptídeos e por fim isolamento com confirmação da sua bioatividade para que dessa forma sejam utilizados para formulação de produtos (Agyei et al., 2016).

Jia et al., (2021) fizeram a análise proteômica do soro do leite caprino e bovino em dois períodos de lactação, o colostro e o soro do leite maduro, constatando que as proteínas e a atividade biológica variam por animal ou por período de lactação. Foram identificadas 487 proteínas sendo estas, 290 no soro caprino colostro e 240 no Soro caprino maduro, 57 proteínas expressas no soro caprino foram identificadas "de forma inédita". Através de análises de bioinformática utilizando as 
proteínas identificadas por espectrometria de massas, observaram que o soro caprino possui proteínas relacionadas a hipoglicemia, catabolismo de lipídios, resposta imunológica, processo metabólico do ATP, ossificação, diminuição da pressão arterial e de atividade molecular estrutural.

Ainda assim, devido à sensibilidade das características das proteínas, os tratamentos aplicados tanto antes, durante e depois da hidrólise devem ser empregados de modo cauteloso, controlados de modo a não provocar alterações que possam levar a perda da funcionalidade (Dullius et al., 2018). Diante das alternativas para utilização dos PBA'S em escala industrial dois fatores devem ser sempre levados em consideração, sendo estes a bioestabilidade e a biodisponibilidade dos peptídeos, pois a manutenção dessas características é essencial para obter efeitos fisiológicos e os peptídeos precisam estar intactos ao atingirem os seus alvos e possam assim exercer sua bioatividade (Mohan et al., 2015).

Nem sempre as pesquisas que envolvem hidrolisados de proteínas avaliam a bioestabilidade e biodisponibilidade dos peptídeos, embora fortes evidências cientificas indiquem que a bioatividade in vitro nem sempre é replicada em modelos animais e em seres humanos (Mohan et al., 2015). Dessa forma as técnicas de encapsulação de bioativos surgem como uma alternativa que proporcionem a manutenção da estrutura do peptídeo intacta durante a digestão gastrointestinal e assim controle a sua liberação fisiológica, resguardando a atividade funcional do peptídeo (Udenigwe, 2014).

\subsubsection{Utilização dos hidrolisados proteicos e peptídeos bioativos por microencapsulação}

A encapsulação é um processo industrial utilizado para o acondicionamento de um material específico (núcleo) em cápsulas que podem ser formuladas a partir de uma variedade de materiais, que liberam os compostos ativos do núcleo em intervalos específicos e variados a depender da cápsula (Champagne \& Fustier, 2007).

Esta tecnologia se tornou relevante para a utilização de bioativos pela indústria alimentar uma vez que possibilita driblar diferentes obstáculos que estão presentes quando se busca aplicar a utilização de moléculas bioativas, principalmente de hidrolisados proteicos, tais como: higroscopicidade dos hidrolisados, hidrofobicidade, sabor amargo e suscetibilidade a degradação total pela digestão no trato gastrointestinal (Fathi et al., 2014; Mohan et al., 2015).

Contudo, para a aplicação da encapsulação é necessário estabelecer e avaliar a influência de fatores relacionados à produção das cápsulas, incluindo o tipo de sistema carreador, o método usado para encapsulação, a pureza e o tipo do material de parede, a relação entre núcleo-parede e as condições de encapsulação. De forma a estabelecer as melhores características que possam culminar em maiores eficiências de encapsulação (Mohan et al., 2015).

A indústria de alimentos opta por selecionar a utilização de materiais de parede que sejam comestíveis, biodegradáveis, não apresente toxicidade e tenham baixo custo. Diante disso a utilização de proteínas, polissacarídeos, lipídios ou a combinação de mais de um tipo de material para a elaboração do material envoltório tem ganhado notoriedade das pesquisas (Fathi et al., 2012; Tavares et al., 2014).

A utilização de proteínas como material de parede ocorre devido as suas características funcionais como elevada solubilidade, formação de um gel firme, capacidade emulsionante, e assim quando combinadas a polissacarídeos tendem a formar cápsulas com maior estabilidade estrutural. Dentre os tipos de proteínas que podem ser utilizadas como materiais de parede estão as proteínas dos derivados de soja, e as proteínas do leite como as caseínas e as proteínas do soro do leite, na sua forma concentrada ou isoladas (Sáiz-Abajo et al., 2013; Mohan et al., 2015).

As proteínas do soro do leite como material de parede vêm sendo descrita por diversos estudos, principalmente utilizando estas proteínas na microencapsulação de probióticos. Doherty et al., (2012) observou maior sobrevivência da cepa Lactobacillus rhamnosus GG ao trato gastrointestinal quando encapsulada em microcápsulas contendo proteínas do soro isoladas e traz a perspectiva de que proteínas do soro do leite podem serem matrizes de retenção eficazes.

Em outro estudo López-Rubio \& Lagaron, (2012) avaliaram a capacidade das proteínas do soro do leite na formação 
de cápsulas, microcápsulas e nanocápsulas por tecnologia de eletropulverização, para encapsulação de $\beta$-caroteno. Estes autores sugerem que o uso das proteínas do soro do leite concentradas como matriz encapsulante ainda é pouco explorado, embora tenha um grande potencial devido às excelentes características funcionais destas proteinas e seu baixo custo de obtenção.

O’Neill et al., (2014) formulou dois tipos de cápsulas contendo riboflavina como núcleo e proteínas do soro do leite concentradas como material de parede a partir de um processo de gelificação a frio e avaliou a eficiência de encapsulação deste bioativo, obtendo maiores quantidades de riboflavina quando as cápsulas feitas de proteínas do soro do leite foram utilizadas como solvente no momento da encapsulação.

No que diz respeito da utilização tanto de hidrolisados proteicos como de peptídeos bioativos do soro do leite como núcleo da encapsulação, diversos estudos têm reportado a potencial eficácia da utilização desta tecnologia embora ainda sejam necessárias mais pesquisas que explorem a encapsulação desta matriz.

Um estudo desenvolvido por Sarabandi et al., (2018) avaliou a microencapsulação de hidrolisados de caseína, as propriedades micro estruturais das cápsulas como teor de umidade, atividade de água, densidade de derivação, solubilidade e higroscopicidade, estrutura química, microestrutura, sabor amargo e atividades antioxidantes. Os autores utilizaram maltodextrina como material de parede e obtiveram as cápsulas por spray-dryer. Os resultados obtidos demonstram maiores atividades antioxidantes dos hidrolisados que foram microencapsulados, menor higroscopicidade destes e assim os autores sugerem que essa é uma tecnologia eficaz para a utilização de hidrolisados da proteína do leite.

Gómez-Mascaraque et al., (2016) elaboraram microcápsulas de quitosana e gelatina por spray-drying para encapsulação de um hidrolisado da proteína do soro do leite potencialmente bioativo, e observaram a estabilidade das cápsulas após a digestão gastrointestinal e a estabilidade dos peptídios quando adicionados a iogurtes (resistência a fermentação ácidolática). Os resultados demonstraram que a maior eficiência de encapsulação foi observada para as cápsulas de quitosana, e não houve alterações no perfil peptídico do hidrolisado digerido.

Outro estudo avaliou a diferença da obtenção de microcápsulas elaboradas a partir de soro do leite concentrado e alginato de sódio por spray-drying e freeze-drying na atividade imunomodulatório, sabor amargo e higroscopicidade de hidrolisados da proteína do soro do leite. Os resultados obtidos indicam que a utilização do spray-drying foi melhor capaz de reduzir o sabor amargo e higroscopicidade sem prejudicar a atividade imunorreguladora do hidrolisado protéico do soro do leite (J.-J. Ma et al., 2014).

Diante da potencial bioatividade dos hidrolisados do soro do leite, são necessários estudos que explorem além da alegação da atividade biológica outras propriedades como a biodisponibilidade, bioestabilidade e assim busquem impulsionar a utilização destas moléculas de forma viável e em uma escala prática para que possam exercer benefício à saúde da população.

\section{Conclusão}

A partir do desenvolvimento deste trabalho de revisão, conclui-se que o leite caprino é uma fonte de componentes funcionais de grande importância nutricional e biológica, onde as proteínas do soro ganham destaque devido a sua diversidade, potencial tecnológico e capacidade de desempenhar efeitos biológicos. Por se tratar de um subproduto barato, obtido em grandes quantidades, o soro do leite desperta um interesse científico expressivo e pertinente, onde trabalhos como este funcionam como instrumento para a prospecção da cadeia produtiva do leite caprino e contribui para a disseminação de informações acerca das proteínas do soro do leite de cabra e suas possíveis aplicações práticas baseadas no seu potencial funcional. 


\section{Referências}

Adeyeye, S. A. O. (2016). Fungal mycotoxins in foods: A review. Cogent Food \& Agriculture, 2(1). https://doi.org/10.1080/23311932.2016.1213127

Agyei, D., Ongkudon, C. M., Wei, C. Y., Chan, A. S., \& Danquah, M. K. (2016). Bioprocess challenges to the isolation and purification of bioactive peptides. Food and Bioproducts Processing, 98, 244-256. https://doi.org/10.1016/j.fbp.2016.02.003

Al-Saadi, J. S., Shaker, K. A., \& Ustunol, Z. (2014). Effect of heat and transglutaminase on solubility of goat milk protein-based films. International Journal of Dairy Technology, 67(3), 420-426. https://doi.org/10.1111/1471-0307.12138

Almaas, H., Eriksen, E., Sekse, C., Comi, I., Flengsrud, R., Holm, H., Jensen, E., Jacobsen, M., Langsrud, T., \& Vegarud, G. E. (2011). Antibacterial peptides derived from caprine whey proteins, by digestion with human gastrointestinal juice. British Journal of Nutrition, 106(6), 896-905. https://doi.org/10.1017/S0007114511001085

Alves, C. Q., David, J. M., David, J. P., Bahia, M. V., \& Aguiar, R. M. (2010). Métodos para determinação de atividade antioxidante in vitro em substratos orgânicos. Química Nova, 33(10), 2202-2210. https://doi.org/10.1590/S0100-40422010001000033

Amalfitano, N., Stocco, G., Maurmayr, A., Pegolo, S., Cecchinato, A., \& Bittante, G. (2020). Quantitative and qualitative detailed milk protein profiles of 6 cattle breeds: Sources of variation and contribution of protein genetic variants. Journal of Dairy Science, 103(12), 11190-11208. https://doi.org/10.3168/jds.2020-18497

Amigo, L., \& Fontecha, J. (2011). Milk| Goat Milk. In Encyclopedia of Dairy Sciences (pp. 484-493). Elsevier. https://doi.org/10.1016/B978-0-12-3744074.00313-7

Araújo, D. F. S., Guerra, G. C. B., Pintado, M. M. E., Sousa, Y. R. F., Algieri, F., Rodriguez-Nogales, A., Araújo, R. F., Gálvez, J., Queiroga, R. de C. R. E., \& Rodriguez-Cabezas, M. E. (2017). Intestinal anti-inflammatory effects of goat whey on DNBS-induced colitis in mice. PLOS ONE, 12(9), e0185382. https://doi.org/10.1371/journal.pone.0185382

Aslam, H., Marx, W., Rocks, T., Loughman, A., Chandrasekaran, V., Ruusunen, A., Dawson, S. L., West, M., Mullarkey, E., Pasco, J. A., \& Jacka, F. N. (2020). The effects of dairy and dairy derivatives on the gut microbiota: a systematic literature review. Gut Microbes, 12(1), 1799533. https://doi.org/10.1080/19490976.2020.1799533

Assis, P. O. A. de, Guerra, G. C. B., Araújo, D. F. de S., Araújo Júnior, R. F. de, Machado, T. A. D. G., Araújo, A. A. de, Lima, T. A. S. de, Garcia, H. E. M., \& Queiroga, R. de C. R. do E. (2016). Intestinal anti-inflammatory activity of goat milk and goat yoghurt in the acetic acid model of rat colitis. International Dairy Journal, 56, 45-54. https://doi.org/10.1016/j.idairyj.2015.11.002

Attaallah, W., Yılmaz, A. M., Erdoğan, N., Yalçın, A. S., \& Aktan, A. Ö. (2012). Whey protein versus whey protein hydrolyzate for the protection of azoxymethane and dextran sodium sulfate induced colonic tumors in rats. Pathology and Oncology Research, 18(4), 817-822. https://doi.org/10.1007/s12253012-9509-9

Azizkhani, M., Saris, P. E. J., \& Baniasadi, M. (2021). An in-vitro assessment of antifungal and antibacterial activity of cow, camel, ewe, and goat milk kefir and probiotic yogurt. Journal of Food Measurement and Characterization, 15(1), 406-415. https://doi.org/10.1007/s11694-020-00645-4

Ballard, K. D., Bruno, R. S., Seip, R. L., Quann, E. E., Volk, B. M., Freidenreich, D. J., Kawiecki, D. M., Kupchak, B. R., Chung, M.-Y., Kraemer, W. J., \& Volek, J. S. (2009). Acute ingestion of a novel whey-derived peptide improves vascular endothelial responses in healthy individuals: a randomized, placebo controlled trial. Nutrition Journal, 8(1), 34. https://doi.org/10.1186/1475-2891-8-34

Batista, M. A., Campos, N. C. A., \& Silvestre, M. P. C. (2018). Whey and protein derivatives: Applications in food products development, technological properties and functional effects on child health. Cogent Food \& Agriculture, 4(1), 1509687. https://doi.org/10.1080/23311932.2018.1509687

Bolacali, M., \& Küçük, M. (2012). Fertility and Milk Production Characteristics of Saanen Goats Raised in Muş Region. Kafkas Universitesi Veteriner Fakultesi Dergisi. https://doi.org/10.9775/kvfd.2011.4895

Brandelli, A., Daroit, D. J., \& Corrêa, A. P. F. (2015). Whey as a source of peptides with remarkable biological activities. Food Research International, 73, 149-161. https://doi.org/10.1016/j.foodres.2015.01.016

Brans, G., Schroën, C. G. P. H., Van Der Sman, R. G. M., \& Boom, R. M. (2004). Membrane fractionation of milk: State of the art and challenges. Journal of Membrane Science, 243(1-2), 263-272. https://doi.org/10.1016/j.memsci.2004.06.029

BRASIL. Ministério da Agricultura, P. e A. (2000). Instrução Normativa no37 de 31 de outubro de 2000. Aprova o Regulamento Técnico de Identidade e Qualidade de Leite de Cabra. Diário Oficial (da República Federativa do Brasil).

Bui-Klimke, T. R., \& Wu, F. (2015). Ochratoxin A and Human Health Risk: A Review of the Evidence. Critical Reviews in Food Science and Nutrition, 55(13), 1860-1869. https://doi.org/10.1080/10408398.2012.724480

Çakır, B., Okuyan, B., Şener, G., \& Tunali-Akbay, T. (2021). Investigation of beta-lactoglobulin derived bioactive peptides against SARS-CoV-2 (COVID19): In silico analysis. European Journal of Pharmacology, 891, 173781. https://doi.org/10.1016/j.ejphar.2020.173781

Ceballos, L. S., Morales, E. R., de la Torre Adarve, G., Castro, J. D., Martínez, L. P., \& Sampelayo, M. R. S. (2009). Composition of goat and cow milk produced under similar conditions and analyzed by identical methodology. Journal of Food Composition and Analysis, 22(4), 322-329. https://doi.org/10.1016/j.jfca.2008.10.020

Champagne, C. P., \& Fustier, P. (2007). Microencapsulation for the improved delivery of bioactive compounds into foods. Current Opinion in Biotechnology, 18(2), 184-190. https://doi.org/10.1016/j.copbio.2007.03.001 
Chauhan, S., Powar, P., \& Mehra, R. (2021). A review on nutritional advantages and nutraceutical properties of cow and goat milk. International Journal of Applied Research, 7(10), 101-105. https://doi.org/10.22271/allresearch.2021.v7.i10b.9025

Clark, S., \& Mora García, M. B. (2017). A 100-Year Review: Advances in goat milk research. Journal of Dairy Science, 100(12), 10026-10044. https://doi.org/10.3168/jds.2017-13287

Contreras, M. del M., Hernández-Ledesma, B., Amigo, L., Martín-Álvarez, P. J., \& Recio, I. (2011). Production of antioxidant hydrolyzates from a whey protein concentrate with thermolysin: Optimization by response surface methodology. LWT - Food Science and Technology, 44(1), 9-15. https://doi.org/10.1016/j.1wt.2010.06.017

Costa Paulino, B., de Souza Aquino, J., Leite de Souza, E., Alencar de Sousa Gomes, J., Paulo Lins, P., Alcoforado Sena de Lima, T., Maria dos Santos Alves, E., \& do Nascimento, E. (2019). Goat Milk Whey Improves Nutritional Status, Fecal Microbial Composition and Intestinal Morphology in Female Rats Fed a Westernized Diet and Their Offspring. Journal of Food and Nutrition Research, 7(4), 291-302. https://doi.org/10.12691/jfnr-7-4-6

Costa, R. G., Freire, R. M. B., de Araújo, G. G. L., Queiroga, R. de C. R. do E., Paiva, G. N., Ribeiro, N. L., Oliveira, R. L., Domínguez, R., \& Lorenzo, J. M. (2021). Effect of Increased Salt Water Intake on the Production and Composition of Dairy Goat Milk. Animals, 11(9), 2642. https://doi.org/10.3390/ani11092642

Coutard, B., Valle, C., de Lamballerie, X., Canard, B., Seidah, N. G., \& Decroly, E. (2020). The spike glycoprotein of the new coronavirus 2019-nCoV contains a furin-like cleavage site absent in CoV of the same clade. Antiviral Research, 176, 104742. https://doi.org/10.1016/j.antiviral.2020.104742

Dalgleish, D. G. (2011). On the structural models of bovine casein micelles-review and possible improvements. Soft Matter, 7(6), 2265-2272. https://doi.org/10.1039/C0SM00806K

De Mejia, E. G., \& Dia, V. P. (2010). The role of nutraceutical proteins and peptides in apoptosis, angiogenesis, and metastasis of cancer cells. Cancer and Metastasis Reviews, 29(3), 511-528. https://doi.org/10.1007/s10555-010-9241-4

Delgadillo-Puga, C., Noriega, L. G., Morales-Romero, A. M., Nieto-Camacho, A., Granados-Portillo, O., Rodríguez-López, L. A., Alemán, G., FuruzawaCarballeda, J., Tovar, A. R., Cisneros-Zevallos, L., \& Torre-Villalvazo, I. (2020). Goat's Milk Intake Prevents Obesity, Hepatic Steatosis and Insulin Resistance in Mice Fed A High-Fat Diet by Reducing Inflammatory Markers and Increasing Energy Expenditure and Mitochondrial Content in Skeletal Muscle. International Journal of Molecular Sciences, 21(15), 5530. https://doi.org/10.3390/ijms21155530

Demers-Mathieu, V., Gauthier, S. F., Britten, M., Fliss, I., Robitaille, G., \& Jean, J. (2013). Antibacterial activity of peptides extracted from tryptic hydrolyzate of whey protein by nanofiltration. International Dairy Journal, 28(2), 94-101. https://doi.org/10.1016/j.idairyj.2012.09.003

Doherty, S. B., Auty, M. A., Stanton, C., Ross, R. P., Fitzgerald, G. F., \& Brodkorb, A. (2012). Survival of entrapped Lactobacillus rhamnosus GG in whey protein micro-beads during simulated ex vivo gastro-intestinal transit. International Dairy Journal, 22(1), 31-43. https://doi.org/10.1016/j.idairyj.2011.06.009

Dullius, A., Goettert, M. I., \& de Souza, C. F. V. (2018). Whey protein hydrolysates as a source of bioactive peptides for functional foods - Biotechnological facilitation of industrial scale-up. Journal of Functional Foods, 42, 58-74. https://doi.org/10.1016/J.JFF.2017.12.063

Esmaeilpour, M., Ehsani, M. R., Aminlari, M., Hoseini, E., \& Azad, I. (2017). Antimicrobial peptides de rived from goat's milk whey proteins obtained by enzymatic hydrolysis. Journal of Food Biosciences and Technology, 7(1), 65-72.

Fathi, M., Martín, Á., \& McClements, D. J. (2014). Nanoencapsulation of food ingredients using carbohydrate based delivery systems. Trends in Food Science \& Technology, 39(1), 18-39. https://doi.org/10.1016/j.tifs.2014.06.007

Fathi, M., Mozafari, M. R., \& Mohebbi, M. (2012). Nanoencapsulation of food ingredients using lipid based delivery systems. Trends in Food Science \& Technology, 23(1), 13-27. https://doi.org/10.1016/j.tifs.2011.08.003

Furlong, S. J., Mader, J. S., \& Hoskin, D. W. (2010). Bovine lactoferricin induces caspase-independent apoptosis in human B-lymphoma cells and extends the survival of immune-deficient mice bearing B-lymphoma xenografts. Experimental and Molecular Pathology, 88(3), 371-375. https://doi.org/10.1016/j.yexmp.2010.02.001

G, G., A, M., A, W., \& H, K. (2016). Review on Goat Milk Composition and its Nutritive Value. Journal of Nutrition and Health Sciences, 3(4). https://doi.org/10.15744/2393-9060.3.401

Gifford, J. L., Hunter, H. N., \& Vogel, H. J. (2005). Lactoferricin. Cellular and Molecular Life Sciences, 62(22), 2588-2598. https://doi.org/10.1007/s00018$005-5373-\mathrm{z}$

Giorgio, D., Di Trana, A., \& Claps, S. (2018). Oligosaccharides, polyamines and sphingolipids in ruminant milk. Small Ruminant Research, 160, 23-30. https://doi.org/10.1016/j.smallrumres.2018.01.006

Gómez-Mascaraque, L. G., Miralles, B., Recio, I., \& López-Rubio, A. (2016). Microencapsulation of a whey protein hydrolysate within micro-hydrogels: Impact on gastrointestinal stability and potential for functional yoghurt development. Journal of Functional Foods, 26 , $290-300$. https://doi.org/10.1016/j.jff.2016.08.006

Gumus, C. E., \& Gharibzahedi, S. M. T. (2021). Yogurts supplemented with lipid emulsions rich in omega-3 fatty acids: New insights into the fortification, microencapsulation, quality properties, and health-promoting effects. Trends in Food Science \& Technology, 110, 267-279. https://doi.org/10.1016/j.tifs.2021.02.016

Haenlein, G. F. W., \& Wendorff, W. L. (2006). Sheep Milk. In Handbook of Milk of Non-Bovine Mammals (pp. 137-194). Blackwell Publishing Professional. https://doi.org/10.1002/9780470999738.ch7

Hammam, A. R. A., Salman, S. M., Elfaruk, M. S., \& Alsaleem, K. A. (2021). Goat Milk: Compositional, Technological, Nutritional, and Therapeutic Aspects. https://doi.org/10.20944/PREPRINTS202108.0097.V1 
Haque, E., \& Chand, R. (2008). Antihypertensive and antimicrobial bioactive peptides from milk proteins. European Food Research and Technology, 227(1), 7-15. https://doi.org/10.1007/s00217-007-0689-6

Hernández-Ledesma, B., Recio, I., \& Amigo, L. (2008). $\beta$-Lactoglobulin as source of bioactive peptides. Amino Acids, 35(2), 257-265. https://doi.org/10.1007/s00726-007-0585-1

Hernández-Ledesma, Blanca, Ramos, M., \& Gómez-Ruiz, J. Á. (2011). Bioactive components of ovine and caprine cheese whey. Small Ruminant Research, 101(1-3), 196-204. https://doi.org/10.1016/j.smallrumres.2011.09.040

Hoffmann, M., Kleine-Weber, H., Schroeder, S., Krüger, N., Herrler, T., Erichsen, S., Schiergens, T. S., Herrler, G., Wu, N.-H., Nitsche, A., Müller, M. A., Drosten, C., \& Pöhlmann, S. (2020). SARS-CoV-2 Cell Entry Depends on ACE2 and TMPRSS2 and Is Blocked by a Clinically Proven Protease Inhibitor. Cell, 181(2), 271-280.e8. https://doi.org/10.1016/j.cell.2020.02.052

Holt, C. (2016). Casein and casein micelle structures, functions and diversity in 20 species. International Dairy Journal, 60, 2-13. https://doi.org/10.1016/j.idairyj.2016.01.004

Ianni, A., Innosa, D., Oliva, E., Bennato, F., Grotta, L., Saletti, M. A., Pomilio, F., Sergi, M., \& Martino, G. (2021). Effect of olive leaves feeding on phenolic composition and lipolytic volatile profile in goat milk. Journal of Dairy Science, 104(8), 8835-8845. https://doi.org/10.3168/jds.2021-20211

IBGE. (2020). Pesquisa da Pecuária Municipal 2020.

Ibrahim, H. R., Ahmed, A. S., \& Miyata, T. (2017). Novel angiotensin-converting enzyme inhibitory peptides from caseins and whey proteins of goat milk. Journal of Advanced Research, 8(1), 63-71. https://doi.org/10.1016/j.jare.2016.12.002

Izzo, L., Luz, C., Ritieni, A., Quiles Beses, J., Mañes, J., \& Meca, G. (2020). Inhibitory effect of sweet whey fermented by Lactobacillus plantarum strains against fungal growth: A potential application as an antifungal agent. Journal of Food Science, 85(11), 3920-3926. https://doi.org/10.1111/1750-3841.15487

J, D.-C., F, L., M, M., MJM, A., MS, C., \& I, L.-A. (2015). Influence of Goat Milk on Iron Deficiency Anemia Recovery. International Journal of Dairy Science \& Processing, 7-11. https://doi.org/10.19070/2379-1578-150003

Jia, W., Zhang, R., Zhu, Z., \& Shi, L. (2021). LC-Q-Orbitrap HRMS-based proteomics reveals potential nutritional function of goat whey fraction. Journal of Functional Foods, 82, 104502. https://doi.org/10.1016/j.jff.2021.104502

Jones, R. G., Ober, C. K., Hodge, P., Kratochvíl, P., Moad, G., \& Vert, M. (2012). Terminology for aggregation and self-assembly in polymer science (IUPAC Recommendations 2013). Pure and Applied Chemistry, 85(2), 463-492. https://doi.org/10.1351/PAC-REC-12-03-12

Kanda, A., Nakayama, K., Fukasawa, T., Koga, J., Kanegae, M., Kawanaka, K., \& Higuchi, M. (2013). Post-exercise whey protein hydrolysate supplementation induces a greater increase in muscle protein synthesis than its constituent amino acid content. British Journal of Nutrition, 110(6), 981-987. https://doi.org/10.1017/S0007114512006174

Kareb, O., \& Aïder, M. (2019). Whey and Its Derivatives for Probiotics, Prebiotics, Synbiotics, and Functional Foods: a Critical Review. Probiotics and Antimicrobial Proteins, 11(2), 348-369. https://doi.org/10.1007/s12602-018-9427-6

Kljajevic, N. V., Tomasevic, I. B., Miloradovic, Z. N., Nedeljkovic, A., Miocinovic, J. B., \& Jovanovic, S. T. (2018). Seasonal variations of Saanen goat milk composition and the impact of climatic conditions. Journal of Food Science and Technology, 55(1), 299-303. https://doi.org/10.1007/s13197-017-2938-4

Koirala, S., Prathumpai, W., \& Anal, A. K. (2021). Effect of ultrasonication pretreatment followed by enzymatic hydrolysis of caprine milk proteins and on antioxidant and angiotensin converting enzyme (ACE) inhibitory activity of peptides thus produced. International Dairy Journal, 118, 105026. https://doi.org/10.1016/j.idairyj.2021.105026

Kong, R., Yang, G., Xue, R., Liu, M., Wang, F., Hu, J., Guo, X., \& Chang, S. (2020). COVID-19 Docking Server: a meta server for docking small molecules, peptides and antibodies against potential targets of COVID-19. Bioinformatics, 36(20), 5109-5111. https://doi.org/10.1093/bioinformatics/btaa645

Korhonen, H. (2009). Milk-derived bioactive peptides: From science to applications. Journal of Functional Foods, 1(2), 177-187. https://doi.org/10.1016/j.jff.2009.01.007

Korhonen, H., \& Pihlanto, A. (2006). Bioactive peptides: Production and functionality. International Dairy Journal, 16(9), 945-960. https://doi.org/10.1016/j.idairyj.2005.10.012

Kosseva, M. R., Panesar, P. S., Kaur, G., \& Kennedy, J. F. (2009). Use of immobilised biocatalysts in the processing of cheese whey. International Journal of Biological Macromolecules, 45(5), 437-447. https://doi.org/10.1016/j.ijbiomac.2009.09.005

Lacroix, I. M. E., \& Li-Chan, E. C. Y. (2013). Inhibition of Dipeptidyl Peptidase (DPP)-IV and $\alpha$-Glucosidase Activities by Pepsin-Treated Whey Proteins. Journal of Agricultural and Food Chemistry, 61(31), 7500-7506. https://doi.org/10.1021/jf401000s

Lacroix, I. M. E., Meng, G., Cheung, I. W. Y., \& Li-Chan, E. C. Y. (2016). Do whey protein-derived peptides have dual dipeptidyl-peptidase IV and angiotensin I-converting enzyme inhibitory activities? Journal of Functional Foods, 21, 87-96. https://doi.org/10.1016/j.jff.2015.11.038

Lestari, P., \& Suyata. (2019). Antibacterial activity of hydrolysate protein from Etawa goat milk hydrolysed by crude extract bromelain. IOP Conference Series: Materials Science and Engineering, 509, 012111. https://doi.org/10.1088/1757-899X/509/1/012111

Liu, Y., Cai, J., \& Zhang, F. (2021). Influence of goat colostrum and mature milk on intestinal microbiota. Journal of Functional Foods, 86, 104704. https://doi.org/10.1016/j.jff.2021.104704

Lopes, F. B., Da Silva, M. C., Miyagi, E. S., Fioravanti, M. C. S., Facó, O., Guimarães, R. F., Júnior, O. A. d. C., \& McManus, C. M. (2012). Spatialization of climate, physical and socioeconomic factors that affect the dairy goat production in Brazil and their impact on animal breeding decisions. Pesquisa Veterinaria Brasileira, 32(11), 1073-1081. https://doi.org/10.1590/S0100-736X2012001100001 
López-Rubio, A., \& Lagaron, J. M. (2012). Whey protein capsules obtained through electrospraying for the encapsulation of bioactives. Innovative Food Science \& Emerging Technologies, 13, 200-206. https://doi.org/10.1016/j.ifset.2011.10.012

Luz, C., Izzo, L., Ritieni, A., Mañes, J., \& Meca, G. (2020). Antifungal and antimycotoxigenic activity of hydrolyzed goat whey on Penicillium spp: An application as biopreservation agent in pita bread. LWT, 118, 108717. https://doi.org/10.1016/j.lwt.2019.108717

Lynch, S. V., \& Pedersen, O. (2016). The Human Intestinal Microbiome in Health and Disease. New England Journal of Medicine, 375(24), $2369-2379$. https://doi.org/10.1056/NEJMra1600266

Ma, J.-J., Mao, X.-Y., Wang, Q., Yang, S., Zhang, D., Chen, S.-W., \& Li, Y.-H. (2014). Effect of spray drying and freeze drying on the immunomodulatory activity, bitter taste and hygroscopicity of hydrolysate derived from whey protein concentrate. LWT - Food Science and Technology, 56(2), 296-302. https://doi.org/10.1016/j.1wt.2013.12.019

Ma, Z., Zhang, F., Ma, H., Chen, X., Yang, J., Yang, Y., Yang, X., Tian, X., Yu, Q., Ma, Z., \& Zhou, X. (2021). Effects of different types and doses of whey protein on the physiological and intestinal flora in D-galactose induced aging mice. PLOS ONE, 16(4), e0248329. https://doi.org/10.1371/journal.pone.0248329

Mangano, K. M., Bao, Y., \& Zhao, C. (2019). Nutritional Properties of Whey Proteins. In Whey Protein Production, Chemistry, Functionality, and Applications. John Wiley \& Sons, Ltd. https://doi.org/10.1002/9781119256052.ch5

Mann, B., Athira, S., Sharma, R., Kumar, R., \& Sarkar, P. (2019). Bioactive Peptides from Whey Proteins. In Whey Proteins (pp. 519-547). Elsevier. https://doi.org/10.1016/B978-0-12-812124-5.00015-1

Mavrommatis, A., \& Tsiplakou, E. (2020). The impact of the dietary supplementation level with Schizochytrium sp. on milk chemical composition and fatty acid profile, of both blood plasma and milk of goats. Small Ruminant Research, 193, 106252. https://doi.org/10.1016/j.smallrumres.2020.106252

Medeiros, G. K. V. V., Queiroga, R. C. R. E., Costa, W. K. A., Gadelha, C. A. A., e Lacerda, R. R., Lacerda, J. T. J. G., Pinto, L. S., Braganhol, E., Teixeira, F. C., Paula, P. P., Campos, M. I. F., Gonçalves, G. F., Pessôa, H. L. F., \& Gadelha, T. S. (2018). Proteomic of goat milk whey and its bacteriostatic and antitumour potential. International Journal of Biological Macromolecules, 113, 116-123. https://doi.org/10.1016/j.ijbiomac.2018.01.200

Mehra, R., Kumar, H., Kumar, N., Ranvir, S., Jana, A., Buttar, H. S., Telessy, I. G., Awuchi, C. G., Okpala, C. O. R., Korzeniowska, M., \& Guiné, R. P. F. (2021). Whey proteins processing and emergent derivatives: An insight perspective from constituents, bioactivities, functionalities to therapeutic applications. Journal of Functional Foods, 87, 104760. https://doi.org/10.1016/j.jff.2021.104760

Mehra, R., Singh, R., Nayan, V., Buttar, H. S., Kumar, N., Kumar, S., Bhardwaj, A., Kaushik, R., \& Kumar, H. (2021). Nutritional attributes of bovine colostrum components in human health and disease: A comprehensive review. Food Bioscience, 40, 100907. https://doi.org/10.1016/j.fbio.2021.100907

Meng, Y., Liang, Z., Zhang, C., Hao, S., Han, H., Du, P., Li, A., Shao, H., Li, C., \& Liu, L. (2021). Ultrasonic modification of whey protein isolate: Implications for the structural and functional properties. LWT, 112272. https://doi.org/10.1016/j.1wt.2021.112272

Minj, S., \& Anand, S. (2020). Whey Proteins and Its Derivatives: Bioactivity, Functionality, and Current Applications. Dairy, 1(3), 233-258. https://doi.org/10.3390/dairy1030016

Mitsiopoulou, C., Sotirakoglou, K., Labrou, N. E., \& Tsiplakou, E. (2021). The effect of whole sesame seeds on milk chemical composition, fatty acid profile and antioxidant status in goats. Livestock Science, 245, 104452. https://doi.org/10.1016/j.livsci.2021.104452

Mohan, A., Udechukwu, M. C., Rajendran, S. R. C. K., \& Udenigwe, C. C. (2015). Modification of peptide functionality during enzymatic hydrolysis of whey proteins. RSC Advances, 5(118), 97400-97407. https://doi.org/10.1039/C5RA15140F

Mollea, C., Marmo, L., \& Bosco, F. (2013). Valorisation of Cheese Whey, a By-Product from the Dairy Industry. In Food Industry. MUZZALUPO, I. Food Industry, Itália: EditoraInTech. https://doi.org/10.5772/53159

Mollica, M. P., Trinchese, G., Cimmino, F., Penna, E., Cavaliere, G., Tudisco, R., Musco, N., Manca, C., Catapano, A., Monda, M., Bergamo, P., Banni, S., Infascelli, F., Lombardi, P., \& Crispino, M. (2021). Milk Fatty Acid Profiles in Different Animal Species: Focus on the Potential Effect of Selected PUFAs on Metabolism and Brain Functions. Nutrients, 13(4), 1111. https://doi.org/10.3390/nu13041111

Monteiro, M. G., Brisola, M. V., \& Filho, J. E. R. V. (2021). TD 2660 - Diagnóstico da Cadeia Produtiva de Caprinos e Ovinos no Brasil. Texto Para Discussão, 1-31. https://doi.org/10.38116/td2660

Moreno-Montoro, M., Olalla-Herrera, M., Rufián-Henares, J. Á., Martínez, R. G., Miralles, B., Bergillos, T., Navarro-Alarcón, M., \& Jauregi, P. (2017). Antioxidant, ACE-inhibitory and antimicrobial activity of fermented goat milk: Activity and physicochemical property relationship of the peptide components. Food and Function, 8(8), 2783-2791. https://doi.org/10.1039/c7fo00666g

Naik, L., Mann, B., Bajaj, R., Sangwan, R. B., \& Sharma, R. (2013). Process optimization for the production of bio-functional whey protein hydrolysates: Adopting response surface methodology. International Journal of Peptide Research and Therapeutics, 19(3), 231-237. https://doi.org/10.1007/s10989-0129340-x

Nascimento, T. V. C., Oliveira, R. L., Menezes, D. R., de Lucena, A. R. F., Queiroz, M. A. Á., Lima, A. G. V. O., Ribeiro, R. D. X., \& Bezerra, L. R. (2021) Effects of condensed tannin-amended cassava silage blend diets on feeding behavior, digestibility, nitrogen balance, milk yield and milk composition in dairy goats. Animal, 15(1), 100015. https://doi.org/10.1016/j.animal.2020.100015

O'Neill, G. J., Egan, T., Jacquier, J. C., O'Sullivan, M., \& Dolores O'Riordan, E. (2014). Whey microbeads as a matrix for the encapsulation and immobilisation of riboflavin and peptides. Food Chemistry, 160, 46-52. https://doi.org/10.1016/j.foodchem.2014.03.002

Osman, A., Goda, H. A., Abdel-Hamid, M., Badran, S. M., \& Otte, J. (2016). Antibacterial peptides generated by Alcalase hydrolysis of goat whey. LWT Food Science and Technology, 65, 480-486. https://doi.org/10.1016/j.lwt.2015.08.043 
Panesar, P. S., Kumari, S., \& Panesar, R. (2013). Biotechnological approaches for the production of prebiotics and their potential applications. Critical Reviews in Biotechnology, 33(4), 345-364. https://doi.org/10.3109/07388551.2012.709482

Park, Young W.; Haenlein, George F. W.; Wendorff, W. L. (2017). Handbook of Milk of Non-Bovine Mammals. In Handbook of Milk of Non-Bovine Mammals (2 nd, p. 712). Wiley-Blackwell Publishers.

Park, Y. W. (2006). Goat Milk-Chemistry and Nutrition. In Handbook of Milk of Non-Bovine Mammals (pp. 34-58). Blackwell Publishing Professional. https://doi.org/10.1002/9780470999738.ch3

Park, Y. W. (2012). Goat Milk and Human Nutrition. Proceedings of the FIRST ASIA DAIRY GOAT CONFERENCE, 1(1), 31-39.

Park, Y. W., \& Haenlein, G. F. W. (2021). A2 Bovine Milk and Caprine Milk as a Means of Remedy for Milk Protein Allergy. Dairy, 2(2), 191-201. https://doi.org/10.3390/dairy2020017

Pawlos, M. (2020). LOW-LACTOSE FERMENTED GOAT MILKS WITH BIFIDOBACTERIUM ANIMALIS SSP. LACTIS BB-12. Journal of Microbiology, Biotechnology and Food Sciences, 9(4), 751-755. https://doi.org/10.15414/jmbfs.2020.9.4.751-755

Pescuma, M., Hébert, E. M., Mozzi, F., \& Font de Valdez, G. (2010). Functional fermented whey-based beverage using lactic acid bacteria. International Journal of Food Microbiology, 141(1-2), 73-81. https://doi.org/10.1016/j.ijfoodmicro.2010.04.011

Prazeres, A. R., Carvalho, F., \& Rivas, J. (2012). Cheese whey management: A review. Journal of Environmental Management, 110, 48-68. https://doi.org/10.1016/j.jenvman.2012.05.018

Pulina, G., Milán, M. J., Lavín, M. P., Theodoridis, A., Morin, E., Capote, J., Thomas, D. L., Francesconi, A. H. D., \& Caja, G. (2018). Invited review: Current production trends, farm structures, and economics of the dairy sheep and goat sectors. Journal of Dairy Science, 101(8), 6715-6729. https://doi.org/10.3168/jds.2017-14015

Queiroz, E. S., Lopes Rezende, A. L., Perrone, Í. T., Francisquini, J. d'Almeida, Fernandes de Carvalho, A., Germano Alves, N. M., Cappa de Oliveira, L. F., \& Stephani, R. (2021). Spray drying and characterization of lactose-free goat milk. LWT, 147, 111516. https://doi.org/10.1016/j.lwt.2021.111516

Ranadheera, C. S., Evans, C. A., Baines, S. K., Balthazar, C. F., Cruz, A. G., Esmerino, E. A., Freitas, M. Q., Pimentel, T. C., Wittwer, A. E., Naumovski, N., Graça, J. S., Sant'Ana, A. S., Ajlouni, S., \& Vasiljevic, T. (2019). Probiotics in Goat Milk Products: Delivery Capacity and Ability to Improve Sensory Attributes. Comprehensive Reviews in Food Science and Food Safety, 18(4), 867-882. https://doi.org/10.1111/1541-4337.12447

Razali, M. F., Narayanan, S., Md. Hazmi, N. A., Abdul Karim Shah, N. N., Mustapa Kamal, S. M., Mohd Fauzi, N. A., \& Sulaiman, A. (2021). Minimal processing for goat milk preservation: Effect of high-pressure processing on its quality. Journal of Food Processing and Preservation, 45(7). https://doi.org/10.1111/jfpp. 15590

Razzaghi, A., Naserian, A. A., Valizadeh, R., Ebrahimi, S. H., Khorrami, B., Malekkhahi, M., \& Khiaosa-ard, R. (2015). Pomegranate seed pulp, pistachio hulls, and tomato pomace as replacement of wheat bran increased milk conjugated linoleic acid concentrations without adverse effects on ruminal fermentation and performance of Saanen dairy goats. Animal Feed Science and Technology, 210, 46-55. https://doi.org/10.1016/j.anifeedsci.2015.09.014

Rubak, Y. T., Nuraida, L., Iswantini, D., \& Prangdimurti, E. (2021). Identification of Angiotensin-I-converting inhibitory peptides in goat milk fermented by lactic acid bacteria isolated from fermented foods and breast milk. Food Science of Animal Resources. https://doi.org/10.5851/kosfa.2021.e55

Saipriya, K., Deshwal, G. K., Singh, A. K., Kapila, S., \& Sharma, H. (2021). Effect of dairy unit operations on immunoglobulins, colour, rheology and microbiological characteristics of goat milk. International Dairy Journal, 121, 105118. https://doi.org/10.1016/j.idairyj.2021.105118

Sáiz-Abajo, M.-J., González-Ferrero, C., Moreno-Ruiz, A., Romo-Hualde, A., \& González-Navarro, C. J. (2013). Thermal protection of $\beta$-carotene in reassembled casein micelles during different processing technologies applied in food industry. Food Chemistry, 138(2-3), 1581-1587. https://doi.org/10.1016/j.foodchem.2012.11.016

Salari, F., Altomonte, I., Ribeiro, N. L., Ribeiro, M. N., Bozzi, R., \& Martini, M. (2016). Effects of season on the quality of Garfagnina goat milk. Italian Journal of Animal Science, 15(4), 568-575. https://doi.org/10.1080/1828051X.2016.1247658

Sarabandi, K., Sadeghi Mahoonak, A., Hamishekar, H., Ghorbani, M., \& Jafari, S. M. (2018). Microencapsulation of casein hydrolysates: Physicochemical, antioxidant and microstructure properties. Journal of Food Engineering, 237, 86-95. https://doi.org/10.1016/j.jfoodeng.2018.05.036

Sarmadi, B. H., \& Ismail, A. (2010). Antioxidative peptides from food proteins: A review. Peptides, 31(10), 1949-1956. https://doi.org/10.1016/j.peptides.2010.06.020

Schulmeister, U., Hochwallner, H., Swoboda, I., Focke-Tejkl, M., Geller, B., Nystrand, M., Härlin, A., Thalhamer, J., Scheiblhofer, S., Keller, W., Niggemann, B., Quirce, S., Ebner, C., Mari, A., Pauli, G., Herz, U., Valenta, R., \& Spitzauer, S. (2009). Cloning, Expression, and Mapping of Allergenic Determinants of $\alpha$ S1-Casein, a Major Cow's Milk Allergen. The Journal of Immunology, 182(11), 7019-7029. https://doi.org/10.4049/jimmunol.0712366

Sgarbieri, V. C. (2004). Propriedades fisiológicas-funcionais das proteínas do soro de leite. Revista de Nutrição, 17(4), 397-409. https://doi.org/10.1590/S1415-52732004000400001

Silanikove, N., Leitner, G., Merin, U., \& Prosser, C. G. (2010). Recent advances in exploiting goat's milk: Quality, safety and production aspects. Small Ruminant Research, 89(2-3), 110-124. https://doi.org/10.1016/j.smallrumres.2009.12.033

Silva, P. D. L. da, Bezerra, M. de F., Santos, K. M. O. dos, \& Correia, R. T. P. (2015). Potentially probiotic ice cream from goat's milk: Characterization and cell viability during processing, storage and simulated gastrointestinal conditions. LWT - Food Science and Technology, 62(1), 452-457. https://doi.org/10.1016/j.lwt.2014.02.055 
Silva, N. N., Casanova, F., Pinto, M. da S., Carvalho, A. F. de, \& Gaucheron, F. (2019). Micelas de caseína: dos monômeros à estrutura supramolecular. Brazilian Journal of Food Technology, 22. https://doi.org/10.1590/1981-6723.18518

Silvestre, M. P. C., Silva, M. R., Silva, V. D. M., Souza, M. W. S. de, Lopes Junior, C. de O., \& Afonso, W. de O. (2012). Analysis of whey protein hydrolysates: peptide profile and ACE inhibitory activity. Brazilian Journal of Pharmaceutical Sciences, 48(4), 747-757. https://doi.org/10.1590/S198482502012000400019

Smithers, G. W. (2008). Whey and whey proteins-From "gutter-to-gold.” International Dairy Journal, 18(7), 695-704. https://doi.org/10.1016/j.idairyj.2008.03.008

Soliman, G. Z. A. (2005). Comparison Of Chemical And Mineral Content Of Milk From Human, Cow, Buffalo, Camel And Goat In Egypt. The Egyptian Journal of Hospital Medicine, 21(1), 116-130. https://doi.org/10.21608/ejhm.2005.18054

Soloshenko, K. I., Lych, I. V., Voloshyna, I. M., \& Shkotova, L. V. (2020). Polyfunctional properties of goat colostrum proteins and their use. Biopolymers and Cell, 36(3), 197-209. https://doi.org/10.7124/bc.000A2B

Sousa, G. T., Lira, F. S., Rosa, J. C., de Oliveira, E. P., Oyama, L. M., Santos, R. V, \& Pimentel, G. D. (2012). Dietary whey protein lessens several risk factors for metabolic diseases: a review. Lipids in Health and Disease, 11(1), 67. https://doi.org/10.1186/1476-511X-11-67

Sung, H., Ferlay, J., Siegel, R. L., Laversanne, M., Soerjomataram, I., Jemal, A., \& Bray, F. (2021). Global Cancer Statistics 2020: GLOBOCAN Estimates of Incidence and Mortality Worldwide for 36 Cancers in 185 Countries. CA: A Cancer Journal for Clinicians, 71(3), 209-249. https://doi.org/10.3322/caac.21660

Tajaddini, M. A., Dayani, O., Khezri, A., Tahmasbi, R., \& Sharifi-Hoseini, M. M. (2021). Production efficiency, milk yield, and milk composition and fatty acids profile of lactating goats feeding formaldehyde-treated canola meal in two levels of dietary crude protein. Small

Ruminant Research, 204, 106519. https://doi.org/10.1016/j.smallrumres.2021.106519

Tavares, G. M., Croguennec, T., Carvalho, A. F., \& Bouhallab, S. (2014). Milk proteins as encapsulation devices and delivery vehicles: Applications and trends. Trends in Food Science \& Technology, 37(1), 5-20. https://doi.org/10.1016/j.tifs.2014.02.008

Tilg, H., Zmora, N., Adolph, T. E., \& Elinav, E. (2020). The intestinal microbiota fuelling metabolic inflammation. Nature Reviews Immunology, 20(1), 4054. https://doi.org/10.1038/s41577-019-0198-4

Turkmen, N. (2017). The Nutritional Value and Health Benefits of Goat Milk Components. In Nutrients in Dairy and their Implications on Health and Disease (pp. 441-449). Elsevier. https://doi.org/10.1016/B978-0-12-809762-5.00035-8

Udenigwe, C. C. (2014). Bioinformatics approaches, prospects and challenges of food bioactive peptide research. Trends in Food Science \& Technology, 36(2), 137-143. https://doi.org/10.1016/j.tifs.2014.02.004

Vankadari, N., \& Wilce, J. A. (2020). Emerging COVID-19 coronavirus: glycan shield and structure prediction of spike glycoprotein and its interaction with human CD26. Emerging Microbes \& Infections, 9(1), 601-604. https://doi.org/10.1080/22221751.2020.1739565

Verruck, S., Dantas, A., \& Prudencio, E. S. (2019a). Functionality of the components from goat's milk, recent advances for functional dairy products development and its implications on human health. Journal of Functional Foods, 52, 243-257. https://doi.org/10.1016/j.jff.2018.11.017

Verruck, S., Dantas, A., \& Prudencio, E. S. (2019b). Functionality of the components from goat's milk, recent advances for functional dairy products development and its implications on human health. Journal of Functional Foods, 52, 243-257. https://doi.org/10.1016/J.JFF.2018.11.017

Watkins, P. J., Jaborek, J. R., Teng, F., Day, L., Castada, H. Z., Baringer, S., \& Wick, M. (2021). Branched chain fatty acids in the flavour of sheep and goat milk and meat: A review. Small Ruminant Research, 200, 106398. https://doi.org/10.1016/j.smallrumres.2021.106398

Xia, S., Lan, Q., Su, S., Wang, X., Xu, W., Liu, Z., Zhu, Y., Wang, Q., Lu, L., \& Jiang, S. (2020). The role of furin cleavage site in SARS-CoV-2 spike protein-mediated membrane fusion in the presence or absence of trypsin. Signal Transduction and Targeted Therapy, 5(1), 92. https://doi.org/10.1038/s41392020-0184-0

Xia, Y., Yu, J., Xu, W., \& Shuang, Q. (2020). Purification and characterization of angiotensin-I-converting enzyme inhibitory peptides isolated from whey proteins of milk fermented with Lactobacillus plantarum QS670. Journal of Dairy Science, 103(6), 4919-4928. https://doi.org/10.3168/jds.2019-17594

Yadav, J. S. S., Yan, S., Pilli, S., Kumar, L., Tyagi, R. D., \& Surampalli, R. Y. (2015). Cheese whey: A potential resource to transform into bioprotein, functional/nutritional proteins and bioactive peptides. Biotechnology Advances, 33(6), 756-774. https://doi.org/10.1016/j.biotechadv.2015.07.002

Zhang, Q.-X., Wu, H., Ling, Y.-F., \& Lu, R.-R. (2013). Isolation and identification of antioxidant peptides derived from whey protein enzymatic hydrolysate by consecutive chromatography and Q-TOF MS. Journal of Dairy Research, 80(3), 367-373. https://doi.org/10.1017/S0022029913000320

Zhou, D.-Y., Zhu, B.-W., Qiao, L., Wu, H.-T., Li, D.-M., Yang, J.-F., \& Murata, Y. (2012). In vitro antioxidant activity of enzymatic hydrolysates prepared from abalone (Haliotis discus hannai Ino) viscera. Food and Bioproducts Processing, 90(2), 148-154. https://doi.org/10.1016/j.fbp.2011.02.002 